\title{
Decadal fingerprints of freshwater discharge around Greenland in a multi-model ensemble
}

\author{
Didier Swingedouw $\cdot$ Christian B. Rodehacke $\cdot$ Erik Behrens • \\ Matthew Menary • Steffen M. Olsen · Yongqi Gao • \\ Uwe Mikolajewicz $\cdot$ Juliette Mignot $\cdot$ Arne Biastoch
}

Received: 20 April 2012/ Accepted: 31 July 2012/Published online: 4 September 2012

(C) Springer-Verlag 2012

\begin{abstract}
The recent increase in the rate of the Greenland ice sheet melting has raised with urgency the question of the impact of such a melting on the climate. As former model projections, based on a coarse representation of the melting, show very different sensitivity to this melting, it seems necessary to consider a multi-model ensemble to tackle this question. Here we use five coupled climate models and one ocean-only model to evaluate the impact of $0.1 \mathrm{~Sv}\left(1 \mathrm{~Sv}=10^{6} \mathrm{~m}^{3} / \mathrm{s}\right)$ of freshwater equally distributed around the coast of Greenland during the historical era 1965-2004. The ocean-only model helps to discriminate between oceanic and coupled responses. In this idealized framework, we find similar fingerprints in the fourth decade of hosing among the models, with a general weakening of the Atlantic Meridional Overturning Circulation (AMOC). Initially, the additional freshwater spreads along
\end{abstract}

\author{
D. Swingedouw $(\bowtie)$ \\ LSCE/IPSL, Gif-sur-Yvette, France \\ e-mail: swingedo@cerfacs.fr \\ C. B. Rodehacke $\cdot$ U. Mikolajewicz \\ Max-Planck-Institut für Meteorologie, Hamburg, Germany \\ E. Behrens $\cdot$ A. Biastoch \\ GEOMAR/Helmhotz Centre for Ocean Research, Kiel, Germany \\ M. Menary \\ Met Office Hadley Centre, Exeter, UK \\ S. M. Olsen \\ DMI, Copenhagen, Denmark \\ Y. Gao \\ NERSC, Bergen, Norway \\ J. Mignot \\ LOCEAN/IPSL, Paris, France
}

the main currents of the subpolar gyre. Part of the anomaly crosses the Atlantic eastward and enters into the Canary Current constituting a freshwater leakage tapping the subpolar gyre system. As a consequence, we show that the AMOC weakening is smaller if the leakage is larger. We argue that the magnitude of the freshwater leakage is related to the asymmetry between the subpolar-subtropical gyres in the control simulations, which may ultimately be a primary cause for the diversity of AMOC responses to the hosing in the multi-model ensemble. Another important fingerprint concerns a warming in the Nordic Seas in response to the re-emergence of Atlantic subsurface waters capped by the freshwater in the subpolar gyre. This subsurface heat anomaly reaches the Arctic where it emerges and induces a positive upper ocean salinity anomaly by introducing more Atlantic waters. We found similar climatic impacts in all the coupled ocean-atmosphere models with an atmospheric cooling of the North Atlantic except in the region around the Nordic Seas and a slight warming south of the equator in the Atlantic. This meridional gradient of temperature is associated with a southward shift of the tropical rains. The free surface models also show similar sea-level fingerprints notably with a comma-shape of high sea-level rise following the Canary Current.

Keywords Greenland ice sheet melting - Thermohaline circulation · Oceanic gyre - Ocean-atmosphere interactions . Oceanic dynamics $\cdot$ Sea-level rise $\cdot$ AMOC $\cdot$ North Atlantic

\section{Introduction}

The Greenland ice sheet (GrIS), the world's second largest ice body after the Antarctic ice sheet, covers presently about $80 \%$ of the surface Greenland and is losing mass at 
an increasing rate. According to Rignot et al. (2011) the total ice mass loss rate in 2010 was around $300 \mathrm{Gt} / \mathrm{yr}$ and the acceleration rate of this melting was about $20 \mathrm{Gt} / \mathrm{yr}^{2}$. If this acceleration rate remains constant in the coming decades, the melting rate of GrIS would be around $2100 \mathrm{Gt} / \mathrm{yr}$ in 2100 , or $0.067 \mathrm{~Sv}$ of freshwater would be added to the ocean along the Greenland coast. The response to an increase in greenhouse gases concentrations in the atmosphere have been evaluated in climate system models that are coupled actively to a GrIS, which is represented by three-dimensional thermo-mechanical ice sheet models like GISM (Huybrechts and de Wolde 1999; Huybrechts et al. 2002) or SICOPOLIS (Greve et al. 1995; Greve 1997) where both models include a visco-elastic model of the solid earth to simulate the isostatic adjustment process. The simulated GrIS melting rates could reach up to more than $0.1 \mathrm{~Sv}$ in the coming centuries, but the rates and spatial patterns scatter considerably between the model simulations (cf. Ridley et al. 2005; Winguth et al. 2005; Mikolajewicz et al. 2007; Driesschaert et al. 2007; Vizcaíno et al. 2010).

The impact of such a melting rate on the ocean circulation can be very important, notably on the Atlantic Meridional Overturning Circulation (AMOC). Changes of the heat transport towards the North Atlantic related to this large-scale oceanic circulation feature has been invoked to explain large-scale climatic changes during the last glacial period (for reviews see Kageyama et al. 2010; Clement and Peterson 2008). Moreover, paleo-reconstructions indicate the occurrence of large freshwater input (the so-called Heinrich events, Heinrich 1988) in the past, with large impacts on climate (Rahmstorf 2002).

Simple models of the AMOC (Stommel 1961; Rooth 1982) have indeed shown the existence of a bifurcation in the phase diagram of the AMOC against freshwater input in the North Atlantic. This has been confirmed by studies with an OGCM (Bryan et al. 1987) and with coupled AOGCMs (Manabe and Stouffer 1988; Hawkins et al. 2011). The typical value of freshwater input to reach the bifurcation point is of the order of $0.1 \mathrm{~Sv}$ for simplified (Rahmstorf et al. 2005) and more complex models (Hawkins et al. 2011). This means that for a large enough freshwater input, the AMOC could show rapid changes, as found in projections in a few models ( $\mathrm{Hu}$ et al. 2011; Swingedouw et al. 2007). Therefore the question of addressing impacts of an enhanced GrIS melting under present-day/near-future conditions is eminent.

This question can be addressed by using numerical OceanAtmosphere or Ocean General Circulation Models (OAGCMS, OGCMs). The latter is then considered in a forced configuration, where all atmospheric fluxes are imposed at the surface. However, in this case, its sensitivity to an additional perturbation can be questioned because of surface restoring. As an example Frankignoul et al. (2009) showed that the AMOC variability differs between OGCMs and coupled climate models; the former being mainly sensitive to sea surface temperature (SST) variations in the convection sites, while the latter are more sensitive to sea surface salinity (SSS) variations. Since coupled climate models have more degrees of freedom, their mean states are, in general, characterized by larger biases, while their response to perturbations is probably more consistent. Coupled climate models showed a very large range of sensitivity to freshwater input: AMOC weakening varying between around $1-10 \mathrm{~Sv}$ after 100 years, when $0.1 \mathrm{~Sv}$ of freshwater is released uniformly over a wide region $\left(50-70^{\circ} \mathrm{N}\right)$ in the North Atlantic (Stouffer et al. 2006). The exact causes leading to such an uncertainty in the AMOC response to a given freshwater input still remain to be unraveled.

Beside the AMOC, additional freshwater input may impact other dynamical components such as the gyre system (Levermann and Born 2007). Moreover, a freshwater input can modify the stability of the water column through changes in the halocline depth. Such a modification can affect the heat capacity of the ocean, the sea-ice cover, and the climate through the albedo feedback (Swingedouw et al. 2009). Finally, changes in AMOC may affect the patterns of sea-level rise (Levermann et al. 2005; Stammer 2008; Lorbacher et al. 2010), modulating regionally the eustatic sea-level rise due to the freshwater input. Evaluating the exact impact of freshwater input from GrIS melting still remains under debate so it seems necessary to use an ensemble of models to draw robust conclusions.

The interactions between the oceanic dynamics and the precise location of freshwater input can be important as shown in several studies (Maier-Reimer and Mikolajewicz 1989; Schiller et al. 1997; Saenko et al. 2007; Mignot et al. 2007; Roche 2009). Additional GrIS melting in the future will be predominantly released around Greenland, since the few ice-shelves or marine-terminating glaciers in Greenland are located in fjords. They will certainly retreat or even disintegrate rapidly in response to global warming as recent observations suggests, where warmer water masses penetrate into the southern fjords (Straneo et al. 2010; Holland et al. 2008) and contributes there to the accelerated retreat of the glaciers terminus (Christoffersen et al. 2011; Walsh et al. 2012). Through so-called dynamical thinning the ice elevations decrease beyond the margins and expose a larger ice area to a lower altitude where melting outbalance accumulation so that the total melt rate raises (Pritchard et al. 2009) as it is confirmed by independent estimates (Sasgen et al. 2012). Thus, the majority of the mass loss will occur through melting of the lower elevated margins and routed as freshwater towards the coasts. The impact of a more realistic distribution of the freshwater input will gain insight from a multi-model framework. 
In this study we evaluate the impact of four decades of additional freshwater released around Greenland in six different models without an interactive ice sheet. Five of them are coupled climate models while one pure OGCM is forced by surface fluxes representing the years 1965-2004. Such an experimental design allows us to evaluate the ability of an OGCM to capture effects of freshwater hosing on the oceanic circulation and to identify the importance of coupled ocean-atmosphere feedbacks. The aims of this study are (1) to identify and understand the robust fingerprints of four decades of additionally discharged Greenlandic freshwater that is realistically released along its coast; (2) to improve our understanding of the mechanisms causing a large spread in simulated AMOC responses to freshwater input.

The paper is organized as follows: we present the experimental design of this study in Sect. 2. In Sect. 3, we first analyze the main results concerning the freshwater spread, the global SST response and oceanic circulation response in the Atlantic Ocean. As a second step we propose a few mechanisms to explain the common features found among the different models as well as the differences for the AMOC response. In Sect. 4, we depict the climatic impact and the sea-level rise signature of the freshwater input. A summary and discussions conclude the paper.

\section{Experimental design}

We analyze simulations from six different models: five coupled OAGCMs and one OGCM. The list of these models as well as their main characteristics is given in Table 1. Note that three out of the six models, including the forced OGCM, are using NEMO (Madec 2008) for the oceanic component, with different resolutions $\left(2^{\circ}\right.$ for
IPSLCM5A, $1^{\circ}$ for EC-Earth, $0.5^{\circ}$ for ORCA05). We call them the "NEMO family" in the following. We also note that the BCM2 model is the only one to be formulated on isopycnal vertical coordinates, while the others are using a z-level coordinate.

The analyzed simulations are integrated over the historical era 1965-2004 (except for HadCM3 and MPI-ESM where the experiments were performed for the period 1960-1999 and 1880-1949, respectively). The choice of this time frame was taken in order to allow the integration of the stand-alone OGCM. This means that the external forcings of the simulations include the increase in greenhouse gases concentrations as well as the modification of aerosol composition in the atmosphere and variations of the natural (solar and volcanic) external forcings over this period of time. For each model, we consider two types of simulations. The transient control simulations correspond to historical simulations without any additional freshwater input. The hosing simulations correspond to historical simulations with an additional freshwater input of $0.1 \mathrm{~Sv}$ released on all the coastal grid points around Greenland (Fig. 1) with a homogenous rate during the period 1965-2004 (1960-1999 for HadCM3, 1880-1949 for MPI-ESM).

HadCM3 starts from a 5,000 years spin-up simulation using Levitus et al. (1998) climatology as oceanic initial conditions and pre-industrial greenhouse gas concentrations as external forcing. From 1859 observed external forcings were applied. The IPSLCM5, MPI-ESM and ECEarth simulations start from a suite of spin-up under preindustrial conditions lasting for some thousand years and followed by historical simulations using observed external forcing from 1850. For ORCA05, before the 1948-2007 control simulation, a 30-year long spin-up period was performed. BCM2 simulation started from 1850 with observed external forcing based on an existing 600 years
Table 1 Description of the participating models (line break in the columns)

\begin{tabular}{llllll}
\hline Model & Institute & Type & Ocean & Atmosphere & Reference \\
\hline HadCM3 & Hadley Centre & OAGCM & No name & HadAM3 & Gordon et al. (2000) \\
& & & $1.25 \times 1.25$, & $91 \times 76$, & \\
& & & L20 & L19 & \\
IPSLCM5A & Institut Pierre Simon & OAGCM & NEMO & LMD5 & Dufresne et al. \\
& Laplace & & $2^{\circ}$, L31 & $96 \times 96$, & (submitted) \\
& & & & L39 & \\
MPI-ESM & MPI & ESM & MPI-OM & ECHAM6 & Jungclaus et al. \\
& & & $1.5^{\circ}$, L40 & T63-L47 & (submitted) \\
ORCA05 & GEOMAR & OGCM & NEMO & CORE.v2 & Biastoch et al. (2008) \\
& & & $0.5^{\circ}$, L46 & Forcing & \\
EC-Earth & DMI & OAGCM & NEMO & IFS & Sterl et al. (2011) \\
& & & $1^{\circ}$, L42 & T159-L31 & \\
BCM2 & NERSC & OAGCM & MICOM & ARPEGE & Otterå et al. (2010) \\
& & & $2.8^{\circ}$, L35 & T63-L31 & \\
& & & isopycnal & & \\
\hline
\end{tabular}


Fig. 1 Map of the grid boxes concerning by the hosing (in blue) for each models. This figure also highlights the differences in resolution in the North Atlantic among the different models. a HadCM3, b IPSLCM5, c MPI-ESM, d EC-Earth, e BCM2 and f ORCA05
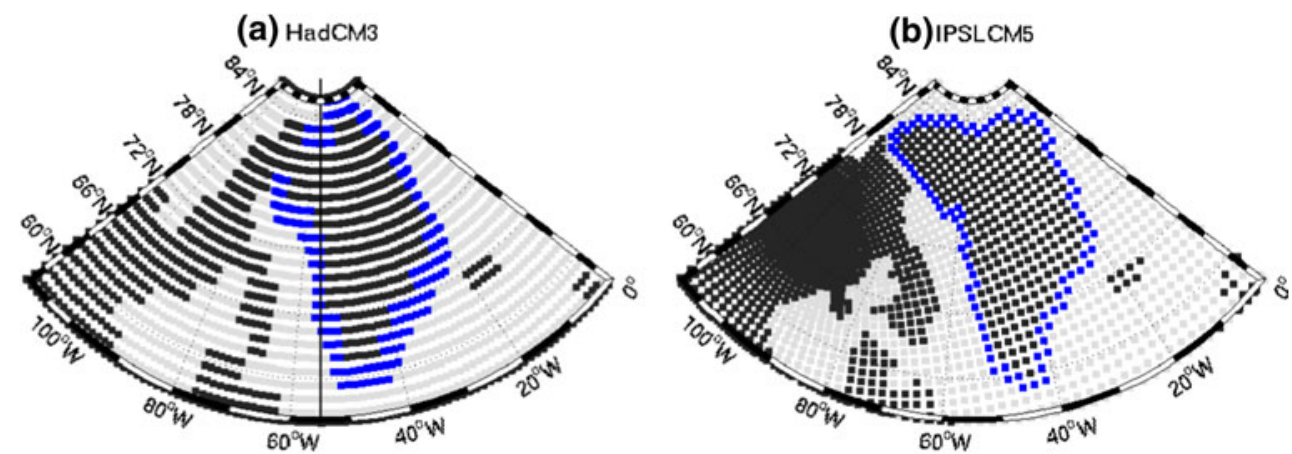

(c) MPI-ESM
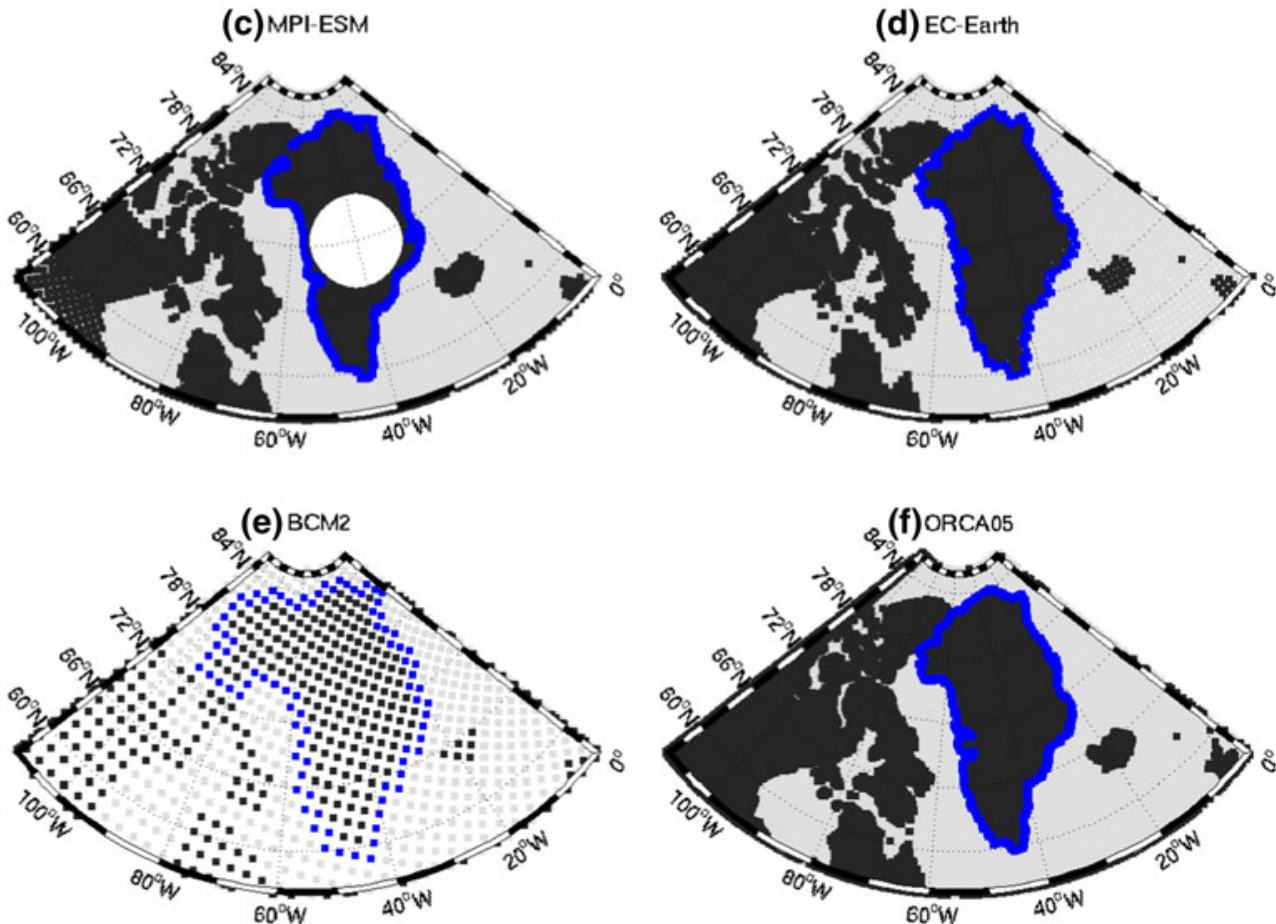

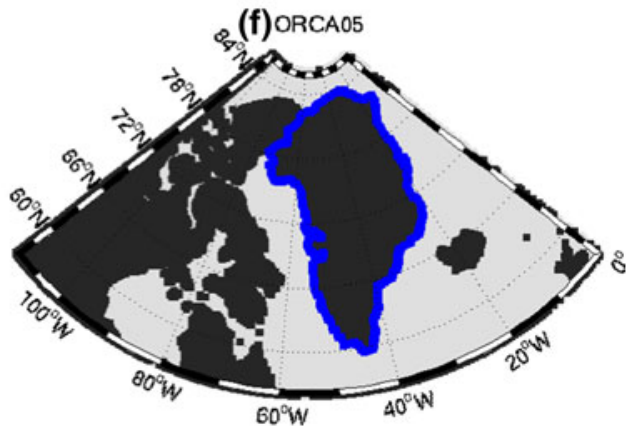

simulation (1400-2000, Otterå et al. 2010). For the MPIESM, we consider a four-member ensemble starting at year 1880, 1890, 1900 and 1910 both for the historical and hosing experiments and lasting 40 years each.

The OGCM setup is based on Biastoch et al. (2008). The simulations are driven by wind, heat and freshwater fluxes using the corrected hindcast CORE.v2 forcing (Large and Yeager 2009). These are applied via bulk formulae at 6-hourly to monthly resolution (depending on the individual forcing component) and they include interannual variability. The OGCM uses a very weak surface relaxation of salinity towards observations (Levitus et al. 1998, merged with PHC (Steele et al. 2001), with a timescale of 365 days, more than two times weaker than in Marsh et al. (2010)). Moreover, in order to allow large salinity anomalies in the hosing experiment, the relaxation is leveled off to a maximum salinity difference of $0.5 \mathrm{PSU}$, if the salinity difference in the restoring term exceeds 0.5 PSU. In this case, the restoring term reaches its maximum value of around $0.2 \mathrm{~mm} / \mathrm{day}$. Furthermore no restoring towards observations is applied in ice-covered regions. This setup allows analyzing the effect of the GrIS melting without inhibiting the impact of the additional freshwater and simultaneously avoids arbitrary oscillations, which could arise with mixed boundary conditions (Gerdes et al. 2006). However, the atmospheric feedback on surface temperatures, which tends to stabilize the AMOC (e.g. Mikolajewicz and Maier-Reimer 1994; Rahmstorf and Willebrand 1995; Nakamura et al. 1994), is not present in this type of model setup. Therefore, rearrangements of the surface fluxes in response to changes in oceanic heat transport and the response of the atmosphere are not represented in ocean-only model.

The fresh water flux treatment in the ocean models from the NEMO family follows the free surface formulation of Roullet and Madec (2000), which ensures salt conservation. In MPI-ESM, meltwater input is treated by changing the surface elevation according to the added meltwater 
volume under conservation of the salt content in the surface box. HadCM3 uses a "rigid lid", in which freshwater fluxes are converted to virtual salt fluxes (Gordon et al. 2000), as it is the case in BCM2. As noted by Yin et al. (2010), virtual salt flux assumption does not have a very large impact on the response to freshwater input as compared to the other formulations.

Concerning the mixing scheme used in the different ocean models, in HadCM3, vertical mixing of tracers is carried out by the K-Theory diffusion using the simplified Large et al. (1994) scheme in the mixed layer. Below, the Pacanowski and Philander (1981) scheme is used. The background tracer diffusion coefficient is a function of depth (Gordon et al. 2000). In the NEMO family, vertical eddy diffusivity and viscosity coefficients are computed from a level 1.5 turbulent closure scheme based on a prognostic equation for the turbulent kinetic energy (Blanke and Delecluse 1993). In the MPI-ESM, the Richardson number-dependent scheme of Pacanowski and Philander (1981) is applied to determine vertical eddy viscosity and diffusion. Near the surface enhanced windinduced mixing is proportional to the cube of the $10-\mathrm{m}$ wind speed that decays exponentially with depth dependent on actual stratification. In BCM2, Gaspar (1988) parameterization is used for the mixed layer dynamics.

In the climate models, the additional freshwater input is not compensated elsewhere, mimicking a net freshwater input from melting land ice. The flux rate of $0.1 \mathrm{~Sv}$ concurs with the experimental design of Stouffer et al. (2006), and is obtained from independent coupled ice sheet-earth system models (Ridley et al. 2005; Mikolajewicz et al. 2007; Vizcaíno et al. 2010) under strong warming climatic conditions for the coming centuries. Such a large freshwater release rate for the period 1965-2004 overestimates the historical freshwater input by an order of magnitude at least (Rignot et al. 2011). We therefore treat the simulations as a high-end estimates and sensitivity experiments designed to identify both the fingerprints of freshwater input along the coast of Greenland and the AMOC sensitivity.

This experimental design allows evaluating the oceanic response via the behaviour of the OGCM within the range of coupled models. Indeed, even though half of the ocean models use the same oceanic model core, differences in, for example, resolution or the implementation of parameterizations, makes it difficult to properly isolate the coupled from the ocean-only response. However, we still gain insights on robust, purely oceanic processes, when both the OGCM and the climate models produce the same fingerprints in response to freshwater input.

All the model transport rates have been calculated on the original model grids while for the figures the outputs have been interpolated on to a common regular $1^{\circ} \times 1^{\circ}$ grid. For all the differences shown hereafter we only present the statistically significant differences in the mean at the $95 \%$ level using a two-tailed student $t$ test. Non-significant areas are shown in white in all the figures.

\section{Results}

\subsection{Freshwater spread and SST response}

The freshwater input along the coast of Greenland has an impact on SSS through its dilution effect and feedbacks. Across the different models the response of the SSS to the freshwater input (differences between hosing and control experiments) shares characteristic similarities (Fig. 2). In the first year of perturbation, most of the negative salinity anomaly is found around the coast of Greenland (not shown). Later the anomaly spreads into the Arctic and Atlantic Oceans in all models, following the main oceanic currents. In the fourth decade after the beginning of the freshwater input, there are large SSS anomalies along the coast of Greenland but also in the subpolar gyre along the North coast of Canada up to the Bering Strait (Fig. 2). In all models except BCM2 we also notice negative SSS anomalies along the western coast of Africa following the Canary Current path (Fedoseev 1970). In the following we denote this anomaly the "freshwater leakage" since it is an important path by which salinity anomalies can escape from the subpolar region. The presence of a negative SSS anomaly in the Nordic Seas is not a robust feature among the models. Similarly, the anomaly is very weak in the center of the subpolar gyre. Interestingly, we notice a positive SSS anomaly in large parts of the Arctic basin in all models (Fig. 2). Its exact position and magnitude (ranging from 0.01 to $0.8 \mathrm{PSU}$ when averaged over the dome north of $85^{\circ} \mathrm{N}$ ) varies among models, but all show positive anomalies in the vicinity of the North Pole. This anomaly will be explored in more detail in Sect. 3.3.3.

Another indirect response to the freshwater input concerns the sea surface temperature (SST). In the fourth decade of continuous hosing, the subpolar gyre has cooled in all the models (Fig. 3). We also notice a cooling along the freshwater leakage path in the models exhibiting such a leakage (which is all except BCM2). South of the equator, in the Atlantic Ocean, we find a slight warming in all the models except BCM2. This SST response resembles a weak bipolar seesaw and is potentially related to AMOC variations (Crowley 1992). The response of the AMOC will be analyzed below. Finally, there is a striking positive SST anomaly in the Nordic Seas again in all the models except BCM2. This warming is rather surprising and will be investigated in details below.

Most of the similar response patterns found across the OAGCMs are also found in the OGCM (fresh and cold 
Fig. 2 Sea surface salinity (SSS) difference between hosing and control experiments averaged over the 4th decade for the different models. Only the $95 \%$ significant anomalies following a student $t$ test are shown. a HadCM3, b IPSLCM5, c MPI-ESM, d EC-Earth, e BCM2 and f ORCA05. The colour interval is 0.2 PSU. The model characteristics are summarized in Table 1. The black box in a masks the area used to quantify the fresh water leakage; details are given in the text

\section{4th decode SSS onomalies}

(a) $\operatorname{HodCM} 3$

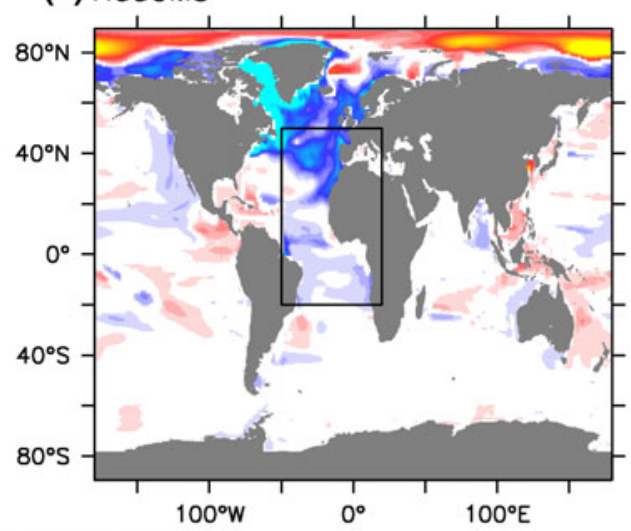

(c) MPI-ESM

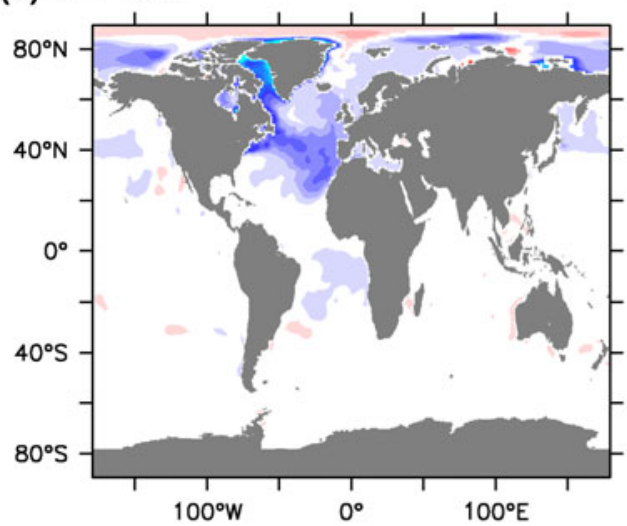

(e) $\mathrm{BCM} 2$

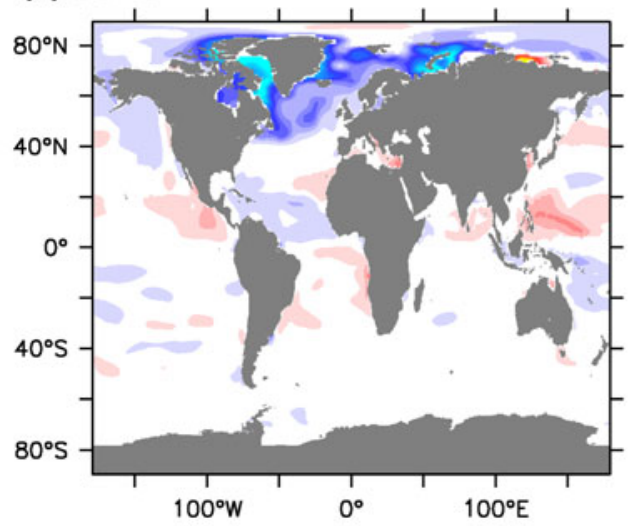

(b) IPSLCM5

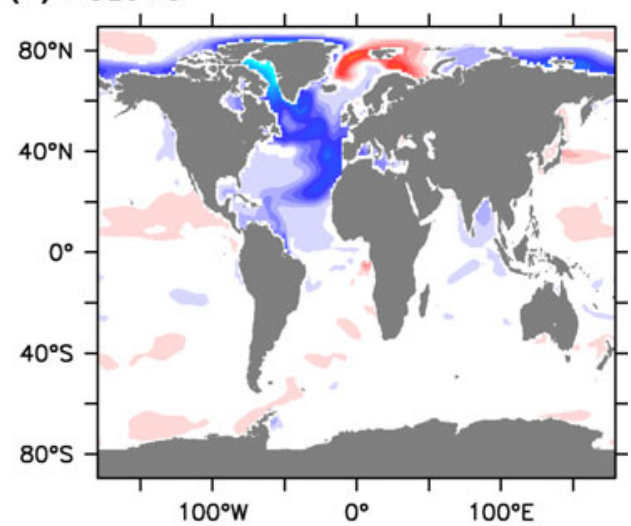

(d) EC-Earth

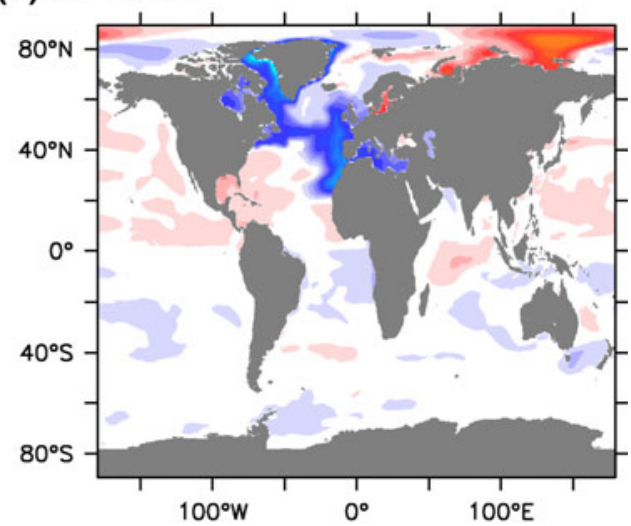

(f) ORCA05

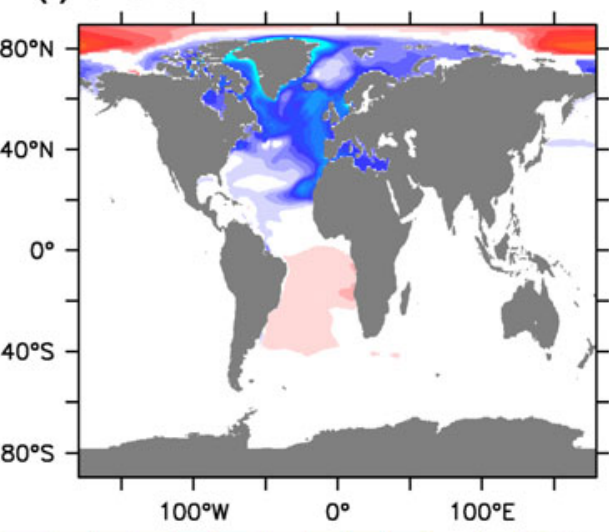

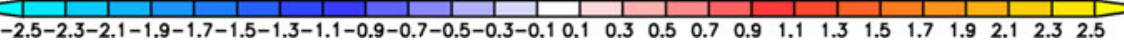

subpolar gyre, freshwater leakage, Arctic SSS positive anomaly, warm Nordic Seas, and inter-hemispheric SST seesaw). This strongly suggests that the mechanisms explaining these fingerprints are related to ocean-only processes. Nevertheless, the magnitude of the different fingerprints varies among the models, which could be related to the different influences of coupled feedbacks.

It is important to stress that despite large-scale similarities after four decades, the temporal evolution of individual fingerprints differs across the analyzed models. In the Labrador Sea and subpolar gyre the SSS negative anomaly appears in the first decade in all the models (not shown). The freshwater leakage takes one to two decades to become significant. The warming of the Nordic Seas requires two to three decades before being significant in most of the models. The positive SSS anomaly in the Arctic is significant only after four decades of hosing in most of the models. 
Fig. 3 Sea surface temperature (SST) difference between hosing and control experiments averaged over the 4 th decade for the different models (unit: ${ }^{\circ} \mathrm{C}$ ). Only the $95 \%$ significant anomalies following a student $t$ test are shown. a HadCM3, b IPSLCM5, c MPI-ESM, d EC-Earth, e BCM2 and f ORCA05. The colour interval is $0.4{ }^{\circ} \mathrm{C}$. The black line represents the annual mean of the sea-ice edge (defined as the $50 \%$ limit) averaged over the 40 years of the control simulation. The red line represents the same sea-ice edge for the observations (Rayner et al. 2003) over the same time period as the transient control simulation of each model
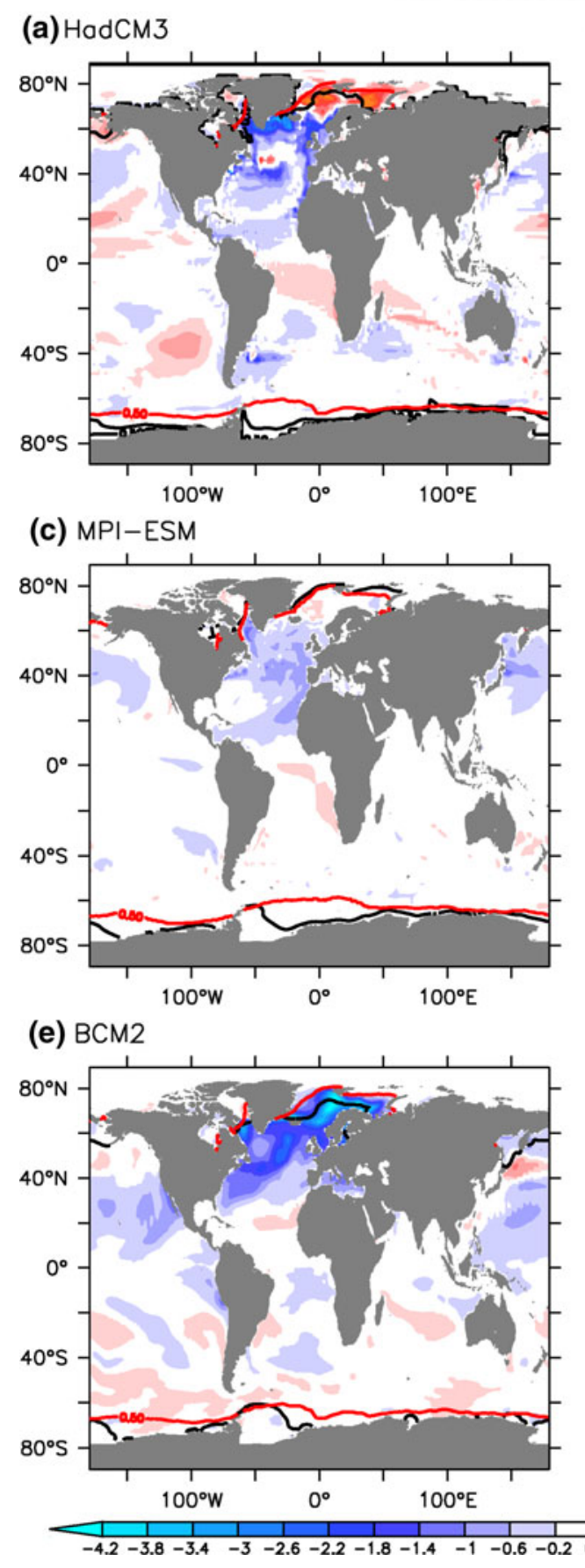

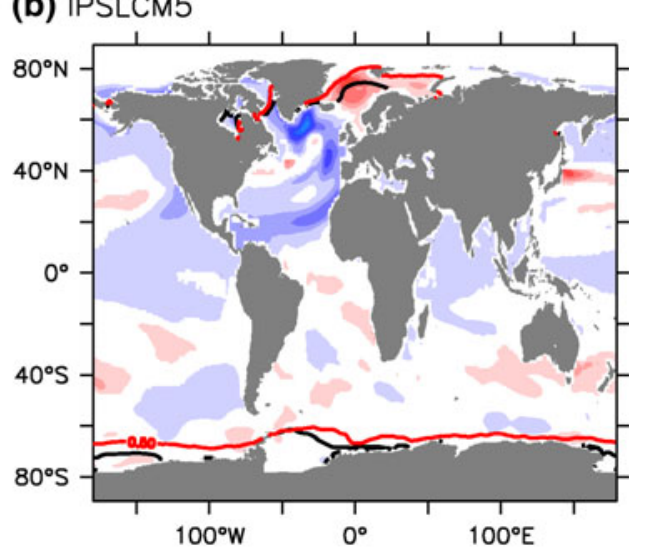

(d) EC-Earth

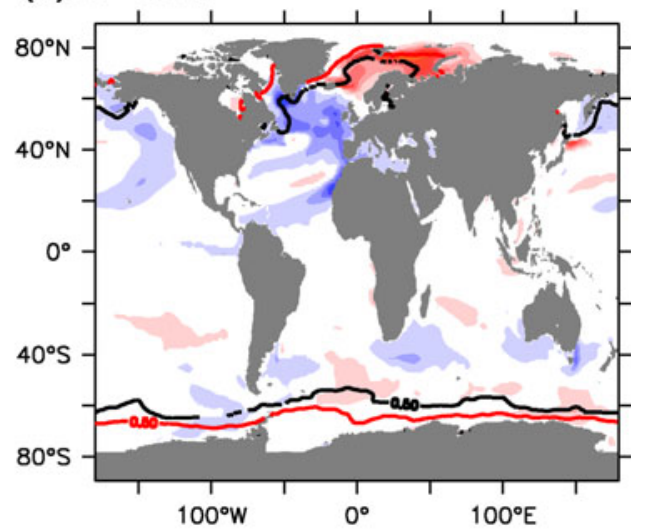

(f) ORCA05

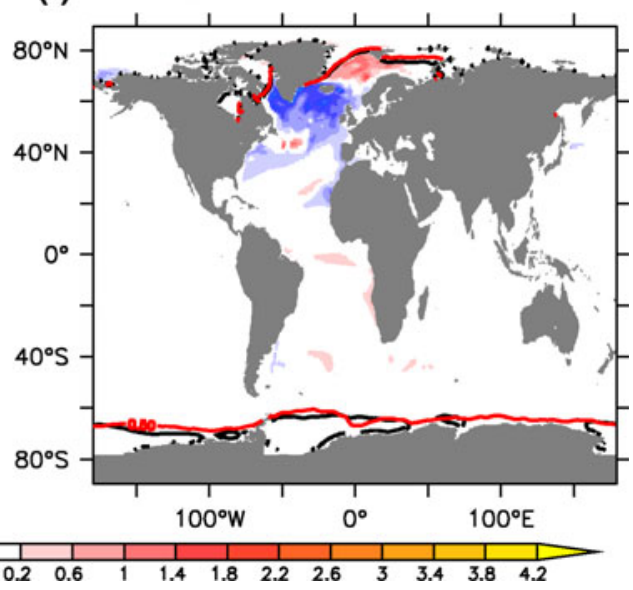

3.2 Impact on the oceanic circulation in the Atlantic

The meridional stream function in the Atlantic averaged over the four decades of the control simulations shares similarities in the six models (Fig. 4, contours). In all of them we find a large structure (the AMOC) transporting water in the top $1,000 \mathrm{~m}$ from the south to the north, sinking around $60^{\circ} \mathrm{N}$ and bringing these waters towards the south at depths from around $1,000 \mathrm{~m}$ down to around $2,500 \mathrm{~m}$ (IPSLCM5) to $4,000 \mathrm{~m}$ (BCM2). The AMOC maximum intensity varies between approximately $10 \mathrm{~Sv}$ (IPSLCM5) and $20 \mathrm{~Sv}$ (BCM2). A reconstruction based on observations (Talley et al. 2003) estimates this maximum to be around $18 \pm 5 \mathrm{~Sv}$. At $26^{\circ} \mathrm{N}$, the AMOC maximum varies between $9.4 \mathrm{~Sv}$ (IPSLCM5) to $16.7 \mathrm{~Sv}$ (BCM2, cf. Table 2), while recent observations estimate this local maximum to be around $18.7 \pm 2.1 \mathrm{~Sv}$ for the years 2004-2008 (Kanzow et al. 2010). All models therefore seem to have a weaker AMOC intensity than observed at $26^{\circ} \mathrm{N}$. The substantial weakness of the AMOC in IPSLCM5 
Fig. 4 Atlantic meridional stream function difference between hosing and control experiments averaged over the 4th decade for the different models (in $\mathrm{Sv}, 1 \mathrm{~Sv}=$ $10^{6} \mathrm{~m}^{3} / \mathrm{s}$ ) Only the $95 \%$ significant anomalies following a student $t$ test are shown. In contours are the control simulation Atlantic meridional stream function averaged over the period 1965-2004 a HadCM3, b IPSLCM5, c MPI-ESM, d EC-Earth, e BCM 2 and $\mathbf{f}$ ORCA05. The colour interval is $0.4 \mathrm{~Sv}$ and the contour line interval is $2 \mathrm{~Sv}$

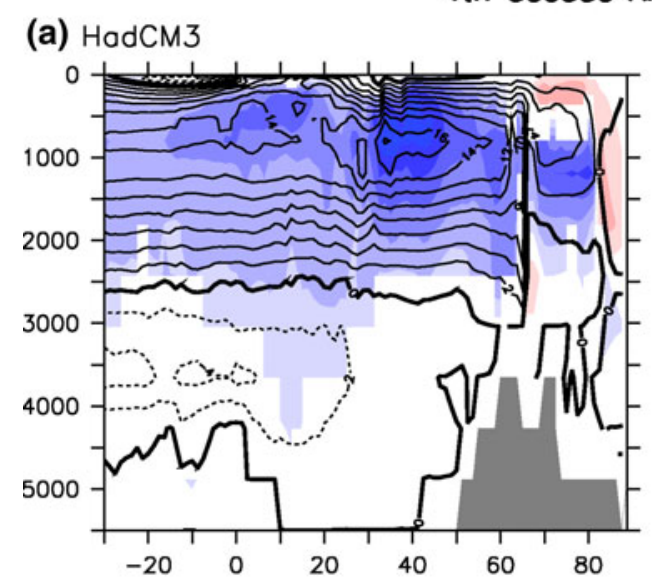

4th decode $A M O C$ onomolies

(b) IPSLCM5
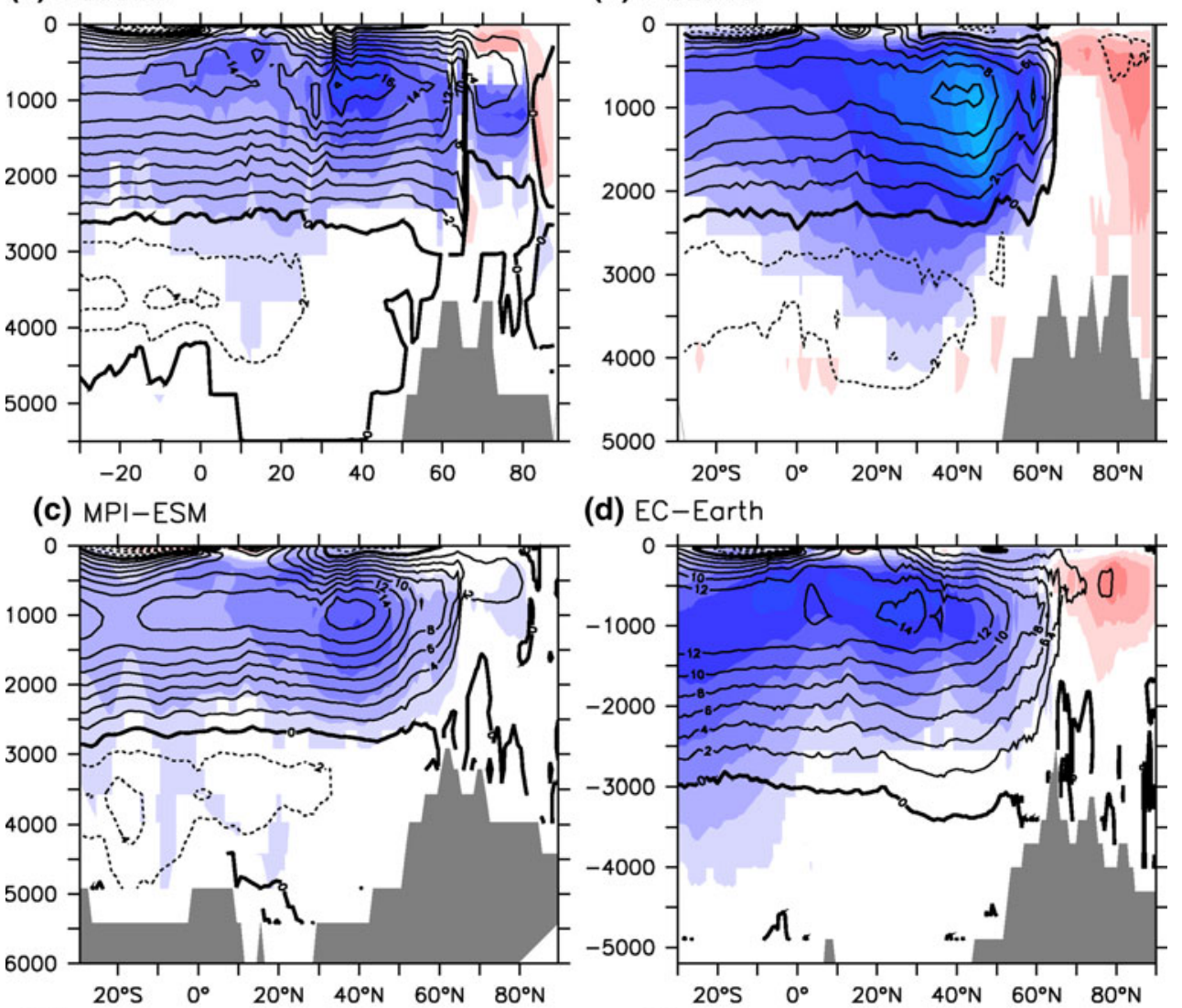

(d) EC-Earth

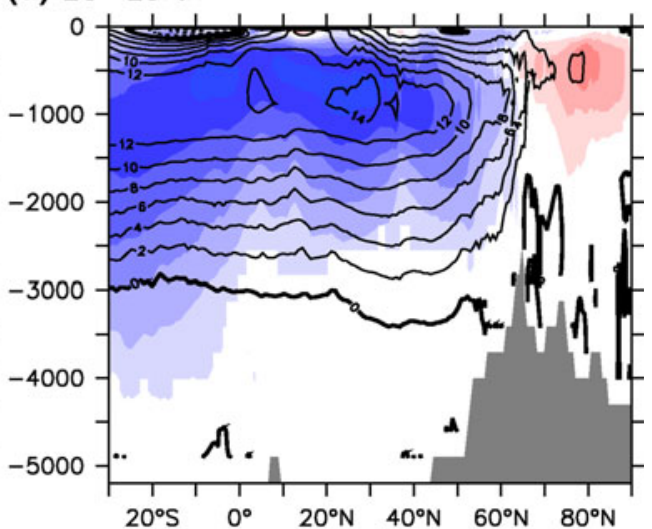

(e) $\mathrm{BCM} 2$

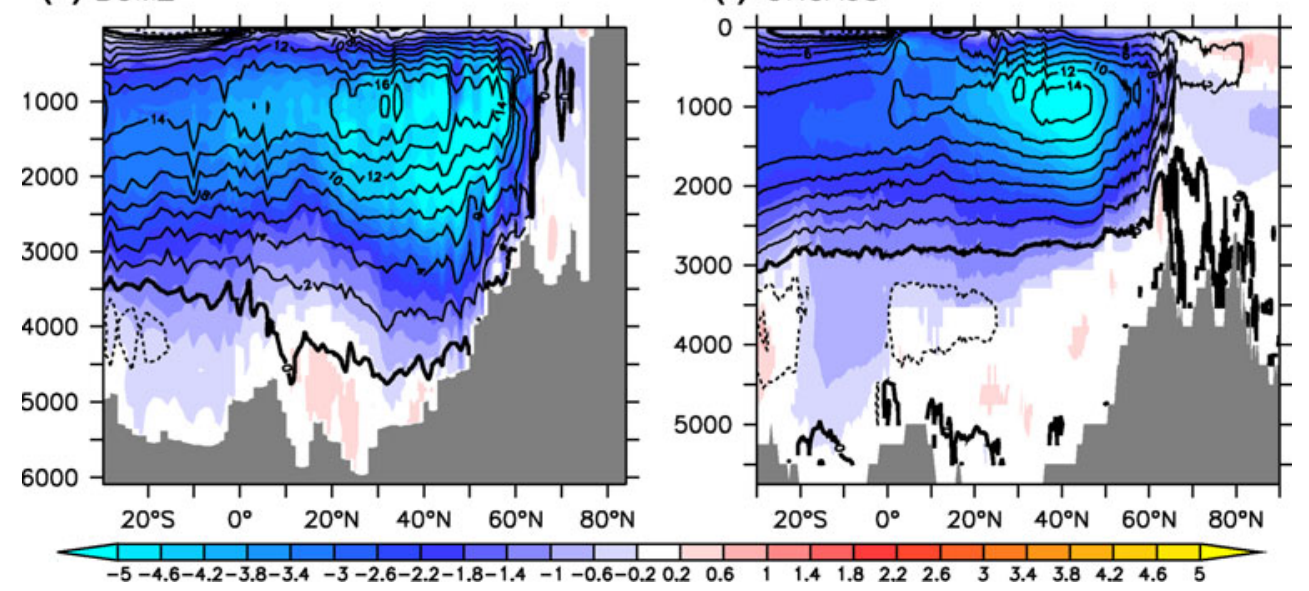

is related to a southward bias of the maximum of the mean zonal wind (Marti et al. 2010) as well as an excess of precipitation in the North Atlantic sector (Swingedouw et al. 2007).

In response to four decades of freshwater input around Greenland, the AMOC weakens in most of the Atlantic Ocean in all the models (Fig. 4, colors). The general weakening of the AMOC is related to the decrease in the mixed layer depth in the northern North Atlantic (Gregory and Tailleux 2011) over this last decade (Fig. 5, colors).
This quantity serves as an indicator of the convective activity in the North Atlantic. Consistent with observations, convection occurs in three different sites in most control simulations (Fig. 5, contours): the Nordic Seas, the Irminger Sea and the Labrador Sea. A major exception is the lack of convection in the Labrador Sea in IPSLCM5, where this site is shifted eastward. After four decades of perturbation, convection in the Labrador Sea has decreased in all the models. In the Irminger Sea the convection also decreases except in BCM2 and to a lesser extent in 
Table 2 Characteristics of the models from control simulations (from 40-year of monthly control simulations)

\begin{tabular}{lrrrrrrr}
\hline Model & HadCM3 & MPI-ESM & \multicolumn{1}{l}{ BCM2 } & IPSLCM5 & EC-Earth & \multicolumn{1}{l}{ ORCA05 } & Observation-based estimates \\
\hline AMOC $26^{\circ} \mathrm{N}(\mathrm{Sv})$ & $14.9(2.5)$ & $15.2(1.5)$ & $16.7(2.4)$ & $9.4(2.0)$ & $15.8(2.6)$ & $15.0(2.5)$ & $18.7 \pm 2.1(\mathrm{Kanzow}$ et al.2010) \\
$\begin{array}{l}\text { Subpolar gyre } \\
\text { min. (Sv) }\end{array}$ & $-19.7(2.4)$ & $-34.2(3.0)$ & $-31.2(5.9)$ & $-26.4(3.2)$ & $-31.6(3.6)$ & $-38.7(5.7)$ & $-40 \pm 8 \mathrm{~Sv}(\mathrm{Böning} \mathrm{et} \mathrm{al.} \mathrm{2006)}$ \\
$\begin{array}{l}\text { Subtropical gyre } \\
\text { max. (Sv) }\end{array}$ & $42.4(3.3)$ & $48.0(3.6)$ & $40.9(3.4)$ & $40.5(5.0)$ & $39.6(3.9)$ & $39.3(2.8)$ & 60 Sv (Johns et al. 1995) \\
\hline
\end{tabular}

The numbers in bracket are the annual mean standard deviation computed over the 40 years of the control simulation

EC-Earth, where the convection is slightly enhanced. In the Nordic Seas, convection is also reduced in most of the models. This convection site slightly shifts to the northwest in both HadCM3 and IPSLCM5, while the shift is southward in BCM2. In the OGCM, the higher spatial resolution and the applied atmospheric forcing, derived from observations, generate a more realistic deep-water formation pattern in the undisturbed case, due to a better representation of the boundary current system around Greenland. However, its general behaviour in response to the freshwater perturbation is similar to the coupled cases: deep convection is reduced after four decades of perturbation (Fig. 5), probably explaining a large part of the AMOC weakening. The response is somewhat stronger than in the coupled models, which could be due to the lack of an atmospheric negative feedback.

In all the models there are two distinct gyres (Fig. 6): the subtropical gyre, extending from around $10^{\circ} \mathrm{N}$ up to $45^{\circ} \mathrm{N}$ flowing clockwise, and the subpolar gyre, extending from around $45^{\circ} \mathrm{N}$ to $65^{\circ} \mathrm{N}$ and flowing anticlockwise. The mean intensity of the subtropical gyre ranges from 39.3 (ORCA05) to $48.0 \mathrm{~Sv}$ (MPI-ESM) and is estimated at around $60 \mathrm{~Sv}$ in observations (Johns et al. 1995), while the intensity of the subpolar gyre (measured negatively given the conventions) ranges from -29.7 (HadCM3) to $-38.7 \mathrm{~Sv}$ (ORCA05) and is estimated at around $-40 \mathrm{~Sv}$ in observations (Böning et al. 2006, cf. Table 2). The differences in these extrema could have several origins, such as differences in wind forcing (intensity and structure), or oceanic parameterization and resolution. In response to the freshwater input, the structure of these gyres is barely affected (not shown). Most noticeable is a slight northward shift of the boundary separating both gyres (defined by the zero line of the barotropic stream function) in the NEMO family for all the decades since the beginning of the perturbation (Fig. 6, color lines). No shift is detected in the three other models. This result indicates that the changes in wind stress (not shown) in the coupled responses are not strong enough to bring significant modifications in the gyre shape within four decades.

In contrast to the structure, the intensity of the gyres is affected by the freshwater input. Their evolutions, as well as the AMOC intensity at $26^{\circ} \mathrm{N}$, are represented in Fig. 7 as a function of time with a 10-year running mean. As indicated above and consistent with Fig. 4, the AMOC maximum at $26^{\circ} \mathrm{N}$ decreases in all the models. After four decades, the absolute slowdown ranges from very weak (less than $2 \mathrm{~Sv}$ ) in both HadCM3 and MPI-ESM to more than $4 \mathrm{~Sv}$ in BCM2 and ORCA05. This general slowdown of the AMOC can be related to the weaker convective activity as indicated earlier. The intensity of the subpolar gyre also weakens in all models except MPI-ESM, but by less than $2 \mathrm{~Sv}$ in EC-Earth and HadCM3 and up to $8 \mathrm{~Sv}$ in BCM2, IPSLCM5, and ORCA05. This is likely related to a reduction of the convective activity since the subpolar gyre strength is strongly modulated by the density contrast between the center of the gyre and its boundary (Levermann and Born 2007). This contrast is itself largely influenced by the deep and intermediate water production. The subtropical gyre shows a very slight weakening $(<2 \mathrm{~Sv})$ in all the models except ORCA05, which shows a pronounced 6.7 Sv decrease in the fourth decade.

\subsection{Proposed mechanisms to explain the main common features}

\subsubsection{Freshwater leakage}

As described above, the dilution signal traced by the negative SSS anomalies spreads along the coast of West Africa and follows the Canary Current in all the models except BCM2 (Fig. 2). This path, that we denote freshwater leakage, is central to understanding the dynamical response across the models. To first order, this signature is primarily related to the advection of the additional freshwater released around Greenland (and partly to a dynamical response): most of the additional GrIS freshwater signal is advected towards the Labrador Sea flowing with the East and West Greenland Currents and through the Davis Strait (not shown). From the Labrador Sea the associated SSS anomalies follow the mean subpolar gyre current southeastward. In the eastern Atlantic the anomaly separates into two branches. One part continues to follow the subpolar gyre and flows towards the Nordic Seas and Irminger Sea. Variations in the separation area between the gyres and the mixing between them enables the rest of the anomaly to 
4th decode max. MLD onomalies

(a) $\operatorname{HadCM} 3$

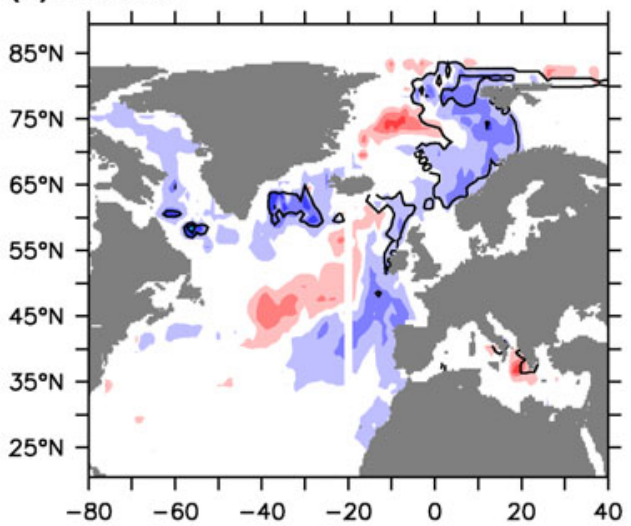

(c) MPI-ESM

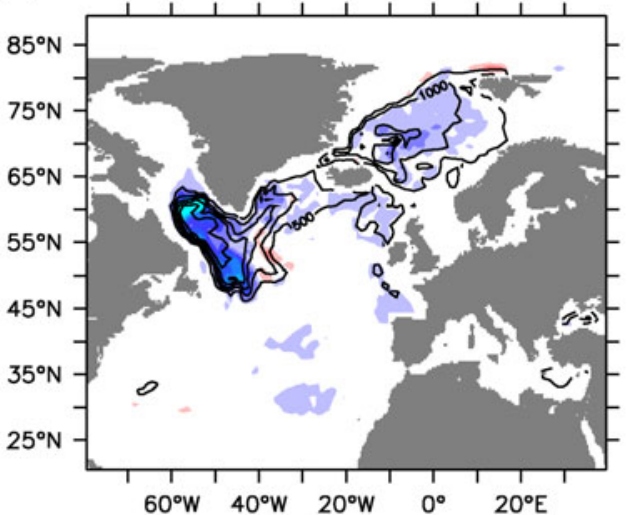

(e) $\mathrm{BCM} 2$

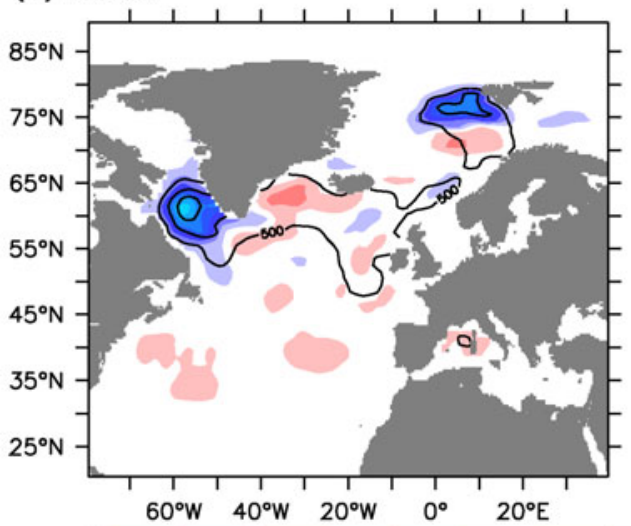

(b) IPSLCM5

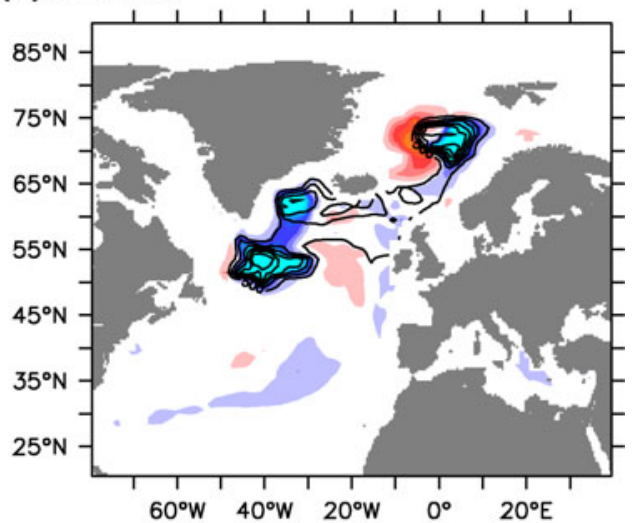

(d) EC-Earth

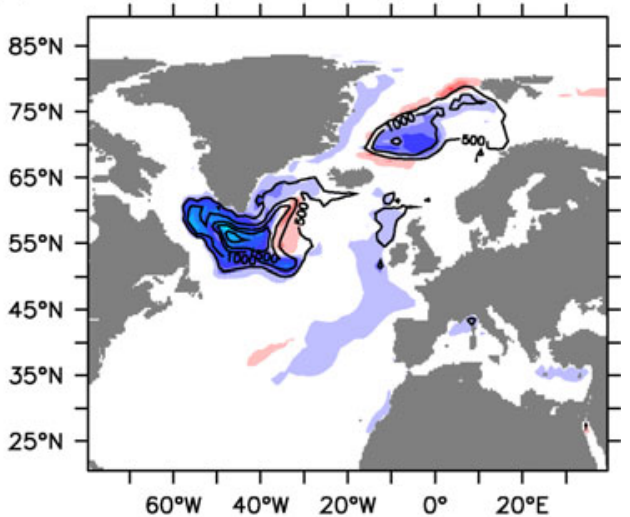

(f) ORCA05

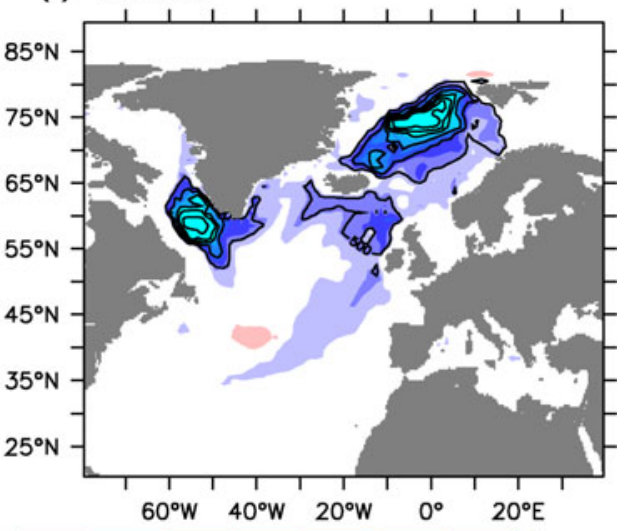

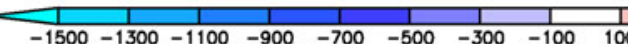

Fig. 5 Difference in the mixed layer depth annual maximum between hosing and control experiments averaged over the 4th decade for the different models (unit: meter). Contoured is the mixed layer depth annual maximum over the period 1965-2004 in the control

spill over into the subtropical gyre, which feeds the southward flowing branch that follows the Canary Current. This freshwater leakage is thus fed by a part of the freshwater perturbation that has left the subpolar gyre and the Nordic Seas. The impact of this freshwater on the convection sites will thus be considerably delayed and possibly simulations. a HadCM3, b IPSLCM5, c MPI-ESM, d EC-Earth, e BCM2 and $\mathbf{f}$ ORCA05. The colour interval is $200 \mathrm{~m}$ and the contour line interval is $500 \mathrm{~m}$

mixed into the main thermocline structure before it possibly reaches again the subpolar North Atlantic (e.g. Mignot and Frankignoul 2005, 2010). Ultimately, for the freshwater perturbation, this leakage may be seen as an important mechanism of "escape" from the convection sites. 
Fig. 6 Barotropic stream function (colours) obtained by integrating vertically the velocity fields and averaged over the 4 decades of the control simulation. The contour interval is $5 \mathrm{~Sv}$. The thick black line indicates the zero line in the control experiments. This line defines the separation between the subpolar (north/blue) and subtropical (south/red) gyres. The other thick coloured lines indicate this zero line averaged for different decades of the hosing experiments (red for decade 1 , green for decade 2 , blue for decade 3 , purple for decade 4). a HadCM3, b IPSLCM5, c MPI-ESM, d EC-Earth, e BCM2 and f ORCA05. Table 1 compares the simulated gyre strengths with estimates based on observations

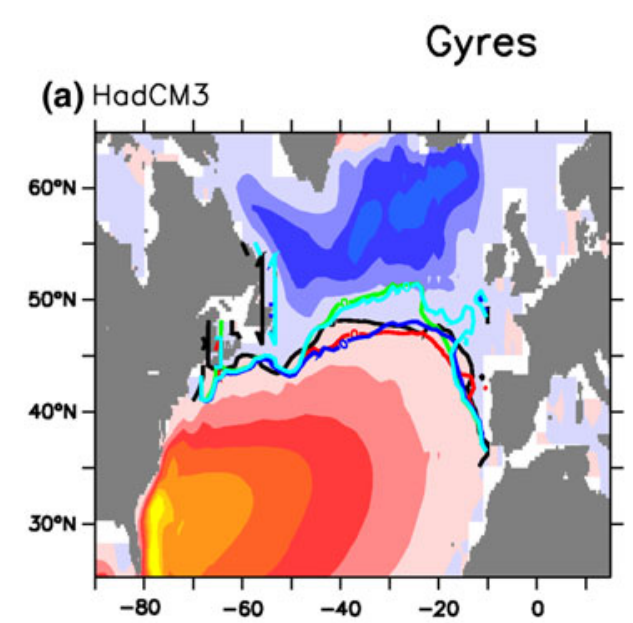

(c) MPI-ESM

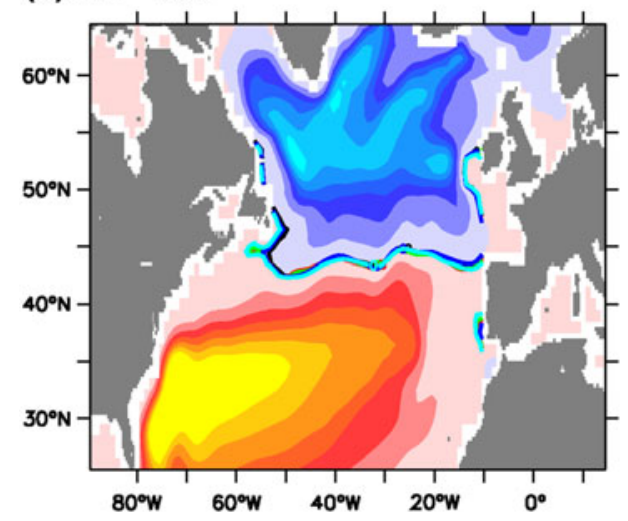

(e) $\mathrm{BCM} 2$

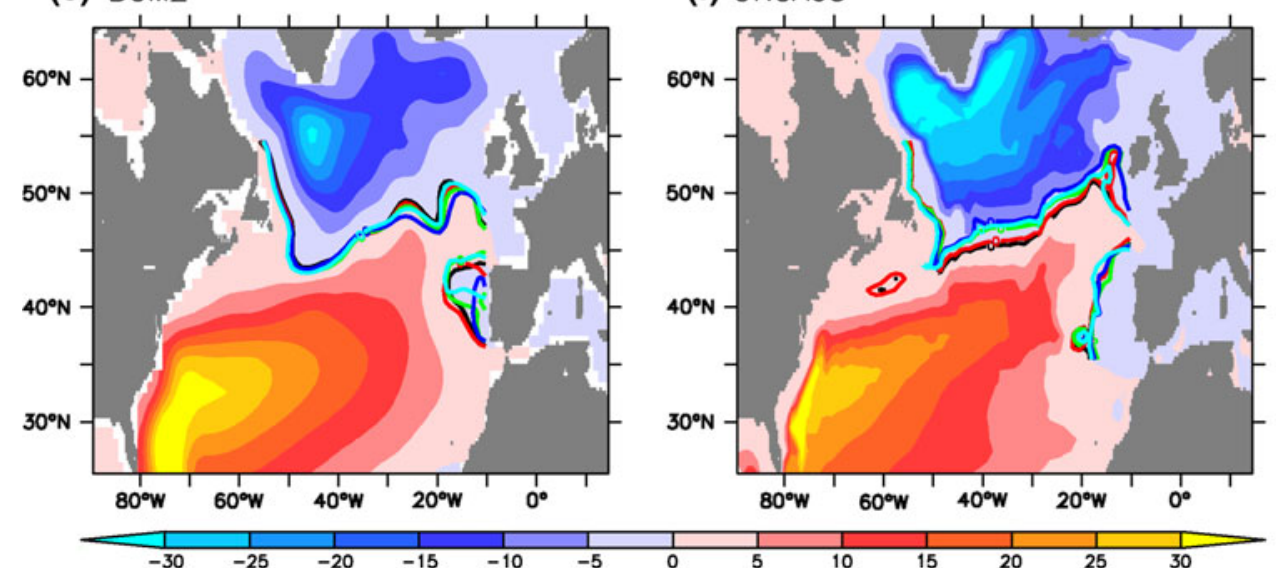

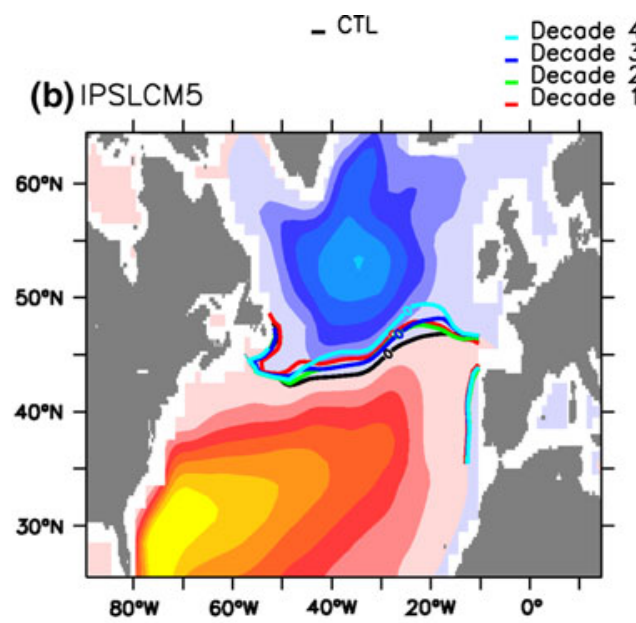

(d) EC-Earth

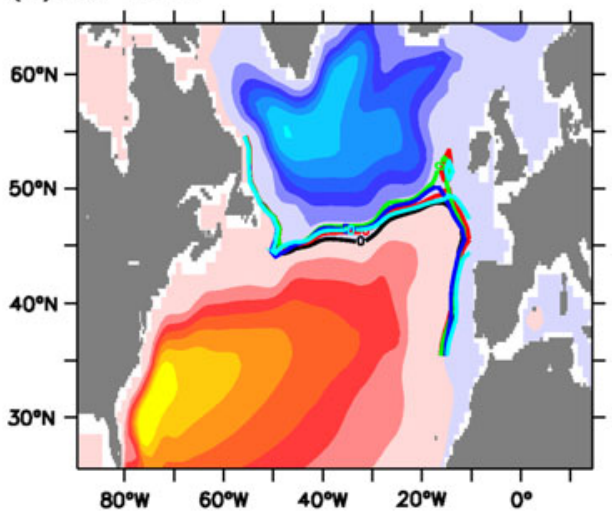

(f) ORCA05
We test diagnostically whether the amount of leakage affects the response of the convective activity and therefore of the AMOC in the models. In order to quantify the leakage, we compute the salinity anomaly over the upper $1,000 \mathrm{~m}$ in an Atlantic box spanning from $50^{\circ} \mathrm{W}$ to $20^{\circ} \mathrm{E}$ and $20^{\circ} \mathrm{S}$ to $50^{\circ} \mathrm{N}$ (box in Fig. 2a). This large box is chosen rather arbitrarily in order to include the subtropical SSS anomalies described above and their extension in the tropics. Its northern limit was chosen to discriminate between the portion of the anomalies pursuing its route in

the subpolar North Atlantic and the part "escaping" the area. Figure 8 suggests that there is a linear relationship $\left(r^{2}=0.67\right.$, significant at the $90 \%$ level $)$ between the salinity decrease in the leakage box defined above and the AMOC decrease at $26^{\circ} \mathrm{N}$. This indicates that models having the weakest leakage into the subtropical gyre exhibit the largest AMOC weakening. Given the number of factors that can affect the spread of AMOC weakening among the different models, these results show that the magnitude of the freshwater leakage may play an 
Fig. 7 Time evolution of different oceanic circulation indices (differences between hosing and control simulations): a Atlantic meridional stream function maximum at $26^{\circ} \mathrm{N}$, b maximum of the barotropic stream function in the Atlantic subtropical gyre, c absolute value of the minimum (minimum: maximal transport due to convention of rotation orientation) of the barotropic stream function in the Atlantic subpolar gyre. HadCM3 is in black, IPSLCM5 is in red, MPIESM is in green, ORCA05 is in blue, EC-Earth is in magenta, BCM2 is in cyan. A 10-year smoothing has been applied to all the time series. The error bars at the end of each time series represent two standard deviations computed in the control simulations
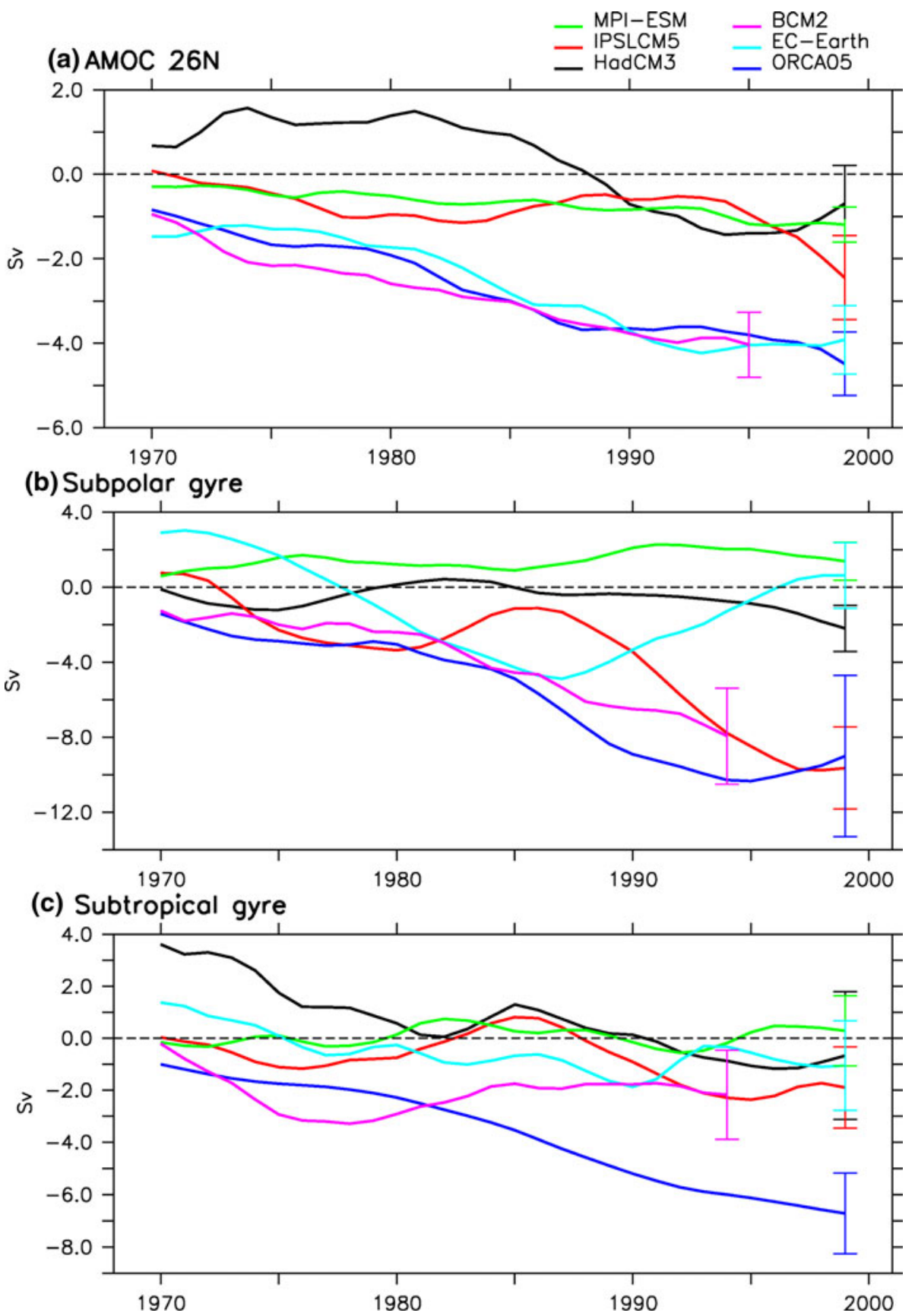

important role for the AMOC weakening in response to a freshwater input. Conversely, if we seek to link the magnitude of AMOC decrease with either the AMOC intensity (cf. Stouffer et al. 2006) or gyre intensity in the control simulations, we find no significant relationships in the model ensemble. This suggests that the modeled AMOC sensitivity to freshwater input is independent of its mean value in the control simulations, as could be deduced from the simple hysteresis curve where the AMOC decreases with freshwater input until reaching a threshold. Here we propose that the AMOC sensitivity is better related to the intensity of the freshwater leakage i.e. the amount of freshwater escaping from the subpolar gyre and Nordic Seas toward the lower latitudes.

A dynamical explanation can be identified by inspecting the slope between the two gyres, which we compute by linear regression of latitude points (against longitude) along the zero line of the barotropic stream function. This is a way to quantify the northeast tilt between the subtropical and subpolar gyre for the 40 years of control simulations (see Fig. 6, slope computed between $50^{\circ} \mathrm{W}-$ $20^{\circ} \mathrm{W}$ and $40^{\circ} \mathrm{N}-50^{\circ} \mathrm{N}$ ). This slope represents the asymmetry between the two gyres and does not appear in quasigeostrophic models (for a symmetric wind forcing, cf. 
Fig. 8 a AMOC changes versus "freshwater leakage" (FW) averaged over the 4th decade. The AMOC changes are defined as the difference between the hosing and control experiments for the AMOC maximum at $26^{\circ} \mathrm{N}$. FW leakage is defined as the averaged salinity anomaly over the region $20^{\circ} \mathrm{S}-50^{\circ} \mathrm{N}$, $50^{\circ} \mathrm{W}-20^{\circ} \mathrm{E}$ up to $1,000 \mathrm{~m}$ depth (black box in Fig. 1a). The black line corresponds to the curve from a least squares linear regression made with the six models $\left(r^{2}=0.67\right)$. The slope is $-14.6 \times 10^{-3} \mathrm{PSU} / \mathrm{Sv}$, b same as a but for the AMOC changes at $26^{\circ} \mathrm{N}$ versus the slope of the gyres $\left(r^{2}=0.88\right)$ computed from a linear regression of the zero line between $45^{\circ} \mathrm{W}-15^{\circ} \mathrm{W}$ and $40^{\circ} \mathrm{N}-50^{\circ} \mathrm{N}$ expressed in degrees of latitude ( ${ }^{\circ}$ Lat) for $10^{\circ}$ of longitude. The error bars at the end of each time series represent two standard deviations computed in the control simulations

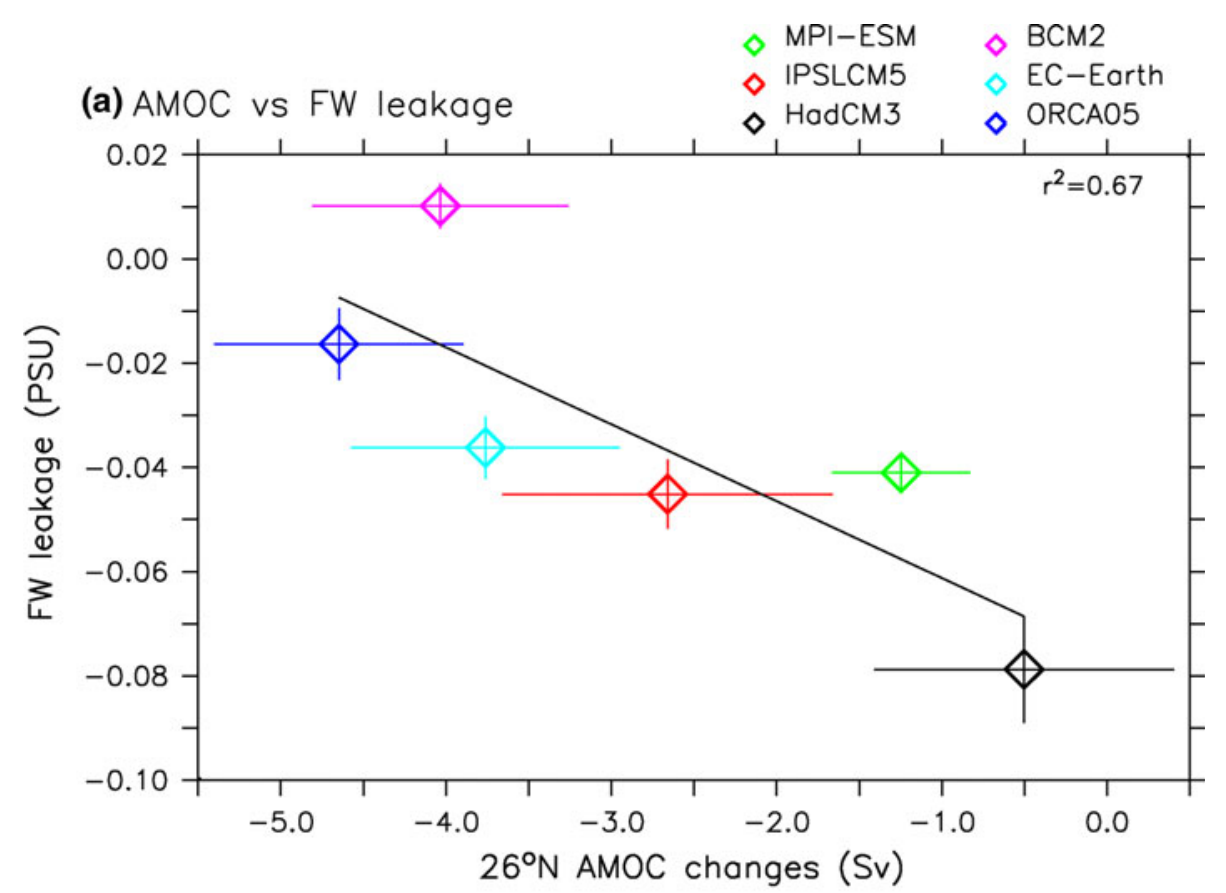

(b) AMOC vs gyres asymmetry

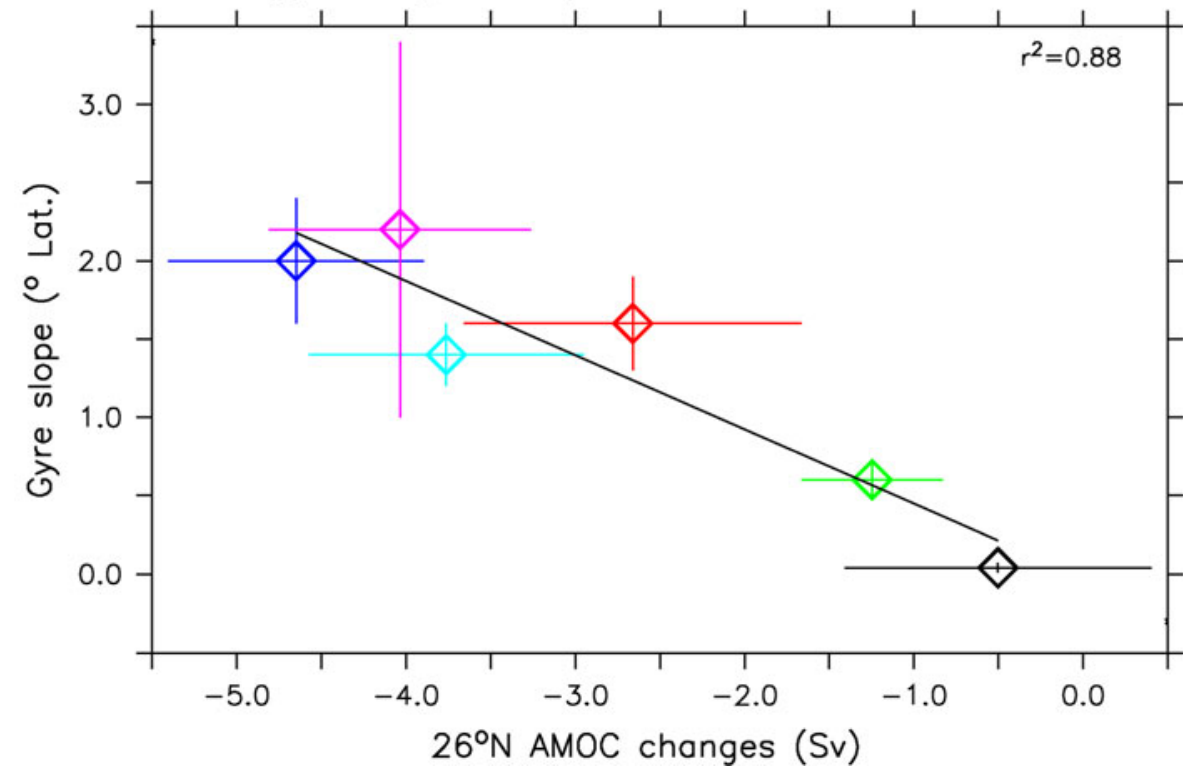

Shimokawa and Matsuura 1999). Regression against the AMOC (Fig. 8b) reveals a significant (95\% level) linear relationship $\left(\mathrm{r}^{2}=0.88\right)$ between this index and the AMOC changes. Our interpretation is: the more zonal the limit between the gyres is, the less water can be transported from the subpolar to the subtropical gyre. In order to explain the differences in the shape of the gyres we have inspected the wind stress curl for the different models but no significant relationship emerges (not shown). The gyre shape results from influences of the topography, which depends on the horizontal resolution, the wind stress forcing as well as other parameterized processes such as eddies. Therefore we cannot necessarily expect to attribute the differences in their shape to a single factor. Nevertheless, here we have shown that the gyre representation strongly impacts the AMOC sensitivity to fresh water input.

\subsubsection{Nordic Seas warming}

In the Nordic Seas, the negative SSS anomaly remains small and confined to the coastal areas in most of the models except BCM2 (Fig. 2). Surprisingly, it is associated with a positive SST anomaly in most of this area in all the models (except BCM2). In contrast, BCM2 shows a 
Fig. 9 Latitude-depth section of the temperature in the Atlantic (averaged over $40^{\circ} \mathrm{W}-$ $\left.0^{\circ} \mathrm{W}\right)$ for the difference between hosing and control experiments averaged over the 4th decade (unit ${ }^{\circ} \mathrm{C}$ ). The contour interval is $0.1{ }^{\circ} \mathrm{C}$. a HadCM3, b IPSLCM5, c MPI-ESM, d EC-Earth, e BCM2 and f ORCA05

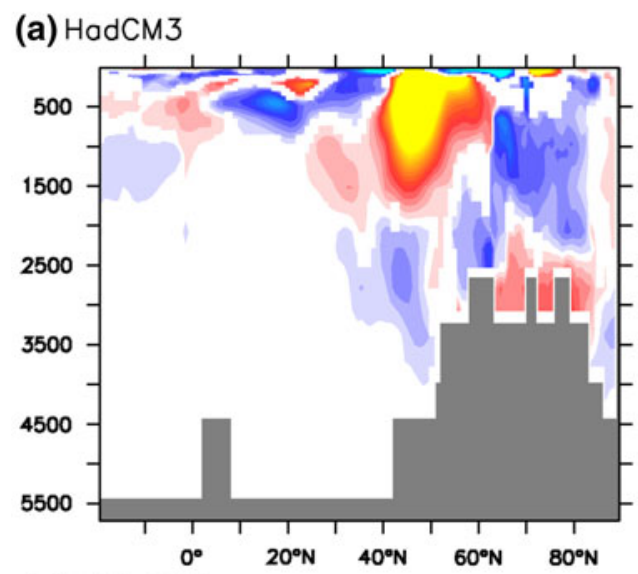

(c) MPI-ESM

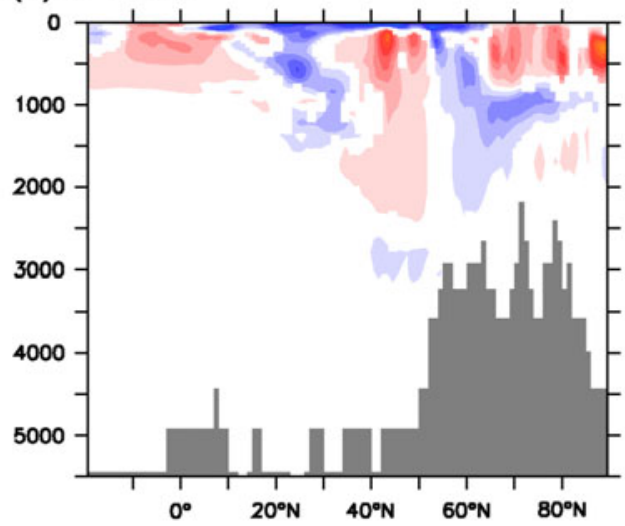

(e) $\mathrm{BCM} 2$

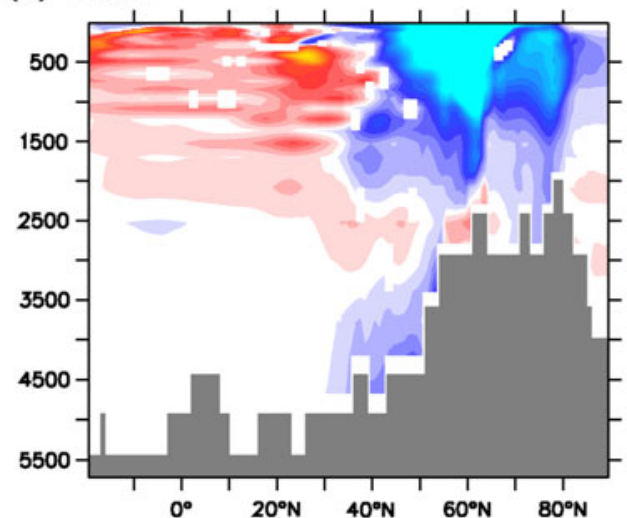

(b) IPSLCM5

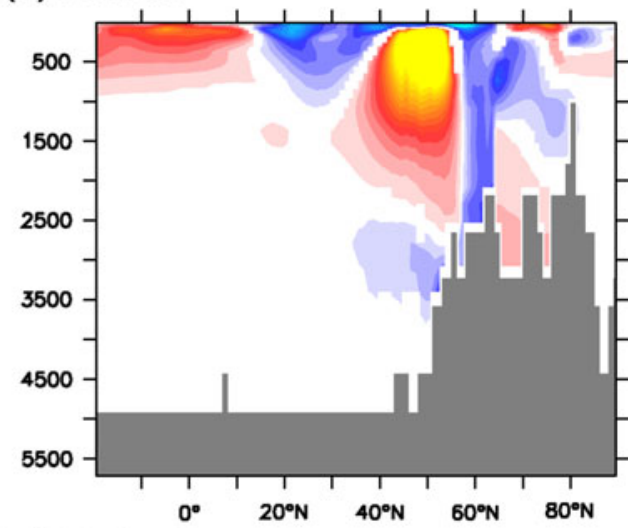

(d) EC-Eorth

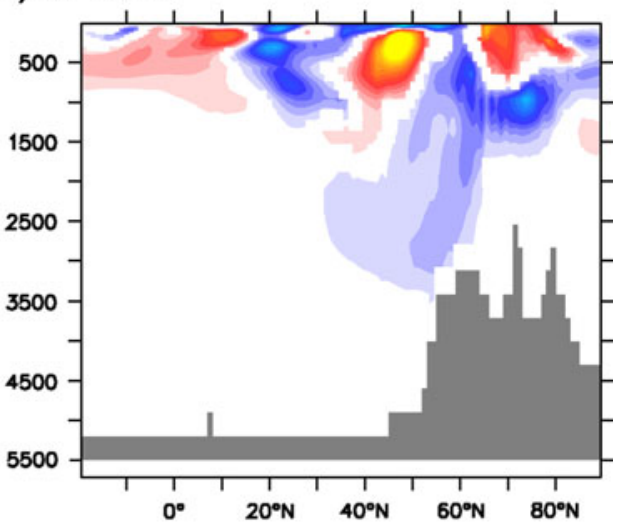

(f) ORCAO5

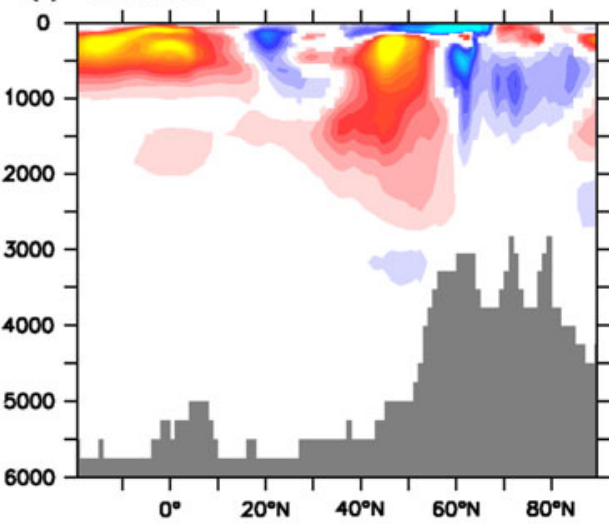

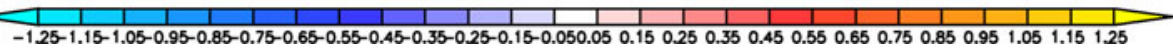

different path for the freshwater spread as compared to the others, since the freshwater leakage is very small in this model and most of the freshwater follows the subpolar gyre and goes towards the Nordic Seas. From the beginning of the experiment in this model a distinct flow of low salinity surface water develops from the East Greenland Current directly to the Nordic Seas, which could explain the strong negative salinity anomaly in the Nordic Seas. This is probably linked to the fact that the model grid only allows for representation of the dynamics of the Denmark Strait across two grid points (cf. Fig. 1) yielding excessive mixing.

In the five other models, in which SST anomalies are found in the Nordic Seas, we notice a subsurface temperature anomaly found around $45^{\circ} \mathrm{N}$ (Fig. 9). These subsurface temperature anomalies can in turn be associated with the freshwater capping of the surface ocean around $40^{\circ} \mathrm{N}$, which hinders the exchange with the surface through convection (e.g. Mignot et al. 2007). As a consequence, part of the subsurface water travelling in the subpolar gyre 
is not mixed with colder surface water, as would otherwise usually be the case through convection. This anomalously warm water mass travels along the eastern side of the Atlantic basin (not shown), eventually reaching the Nordic Seas where its excess of heat re-emerges at the surface due to winter deepening of the mixed layer. The relatively weak freshwater capping at this location facilitates its occurrence. Note that the zonal mean picture in Fig. 9 does not illustrate this continuous path because of the averaging with the cold waters formed further west around $60^{\circ} \mathrm{N}$. Temperature anomalies in the inflowing waters therefore heat the Nordic Seas as compared to the control simulation. Indeed, we find a net increase of northward heat transport across the Iceland-Scotland ridge (not shown). Such a mechanism of subsurface advection of Atlantic water towards the Nordic Seas, when a freshwater perturbation is released uniformly across the entire North Atlantic, has been discussed in others studies (e.g. Kleinen et al. 2009; Mignot et al. 2007). Here we find that it seems robust in this refined experiment mimicking GrIS melting across a range of models.

As a consequence of this heat anomaly, the sea-ice cover fraction is reduced in the Nordic Seas (Fig. 10). Negative anomalies in sea-ice cover fraction are also found in the Barents and Kara Seas in most models (HadCM3, ECEarth, ORCA05, and IPSLCM5). In contrast, sea-ice cover fraction increases in the Labrador Sea where convective activity is largely diminished in most models and stratification favors sea ice formation. We also note in Fig. 3 that the warming magnitude seems to be related to the sea ice edge in the Nordic Seas in the control simulations: MPIESM has small sea-ice cover in the Nordic Seas (in agreement with observations) in the control simulation and its warming is very small in the hosing simulations compared to the NEMO family and HadCM3 where large warming occurs along and above the sea-ice edge (which have an overestimated extension in most of coupled models except MPI-ESM).

\subsubsection{Arctic salinification}

In the Arctic Ocean, Atlantic waters can be found in both observations and the control simulations and they are characterized by a local temperature maximum found around $400 \mathrm{~m}$ in the Arctic (Fig. 11). In the hosing simulations, the subsurface heat anomaly in the Atlantic flows along the usual paths into the Nordic Seas described above also enters the Arctic Ocean in the subsurface, and, ultimately, appears in the surface. Changes in the Atlantic source water masses and the mixing with the freshwater input contributes to modification of the water masses in the Arctic. Indeed, we argue that such modifications explain the surprising positive SSS anomaly found around the
North Pole in all the models (Fig. 12). The northward freshwater transport across the Barents Sea actually decreases in all simulations (not shown). This can be attributed to the increase in the volume of North Atlantic surface and subsurface waters entering the Arctic, due the decrease of convection in the Nordic Seas that limits the production of deep water and therefore the transformation of Atlantic water into North Atlantic deep water. The increase in the overturning north of $60^{\circ} \mathrm{N}$ observed in four out of six of the models (Fig. 4) may also contribute to the increased inflow of Atlantic waters into the Arctic. These water masses from the Atlantic have a higher salinity compared to the polar Arctic waters, which explains the positive SSS anomaly fingerprint. In addition, as in the Nordic Seas, the arrival of these warmer waters tends to reduce the sea-ice cover fraction (Fig. 10), which constitutes a negative feedback, since the melting reduces the SSS positive anomaly. This feedback is nevertheless not strong enough to invert the original signal. This whole mechanism, implying modifications in water mass characteristics in the Arctic, is supported by the changes in stratification around the North Pole (Figs. 11, 13). There we notice in the hosing simulation an increase in salinity in the first few hundred meters as compared to the control simulations in all the models except BCM2 (Fig. 13). This is associated with an increase in subsurface temperatures that does not extend to the surface (Fig. 11), indicating that more Atlantic water may be entering the Arctic. At the surface an increasing Atlantic water fraction may contribute to the positive SSS anomaly, while the SST changes are damped through air-sea interactions and sea ice melting.

\subsection{Climatic impact and sea level rise signature}

\subsubsection{Temperature and precipitation response}

After four decades of additional GrIS freshwater input, all coupled models show a significant widespread cooling of the 2-m air temperature over the North Atlantic (Fig. 14). The pattern of this cooling follows the SST pattern (Fig. 3) and its characteristic "comma" shape appears along the west coast of Africa (except in BCM2) and follows the Canary Current. The second striking common pattern found in most models is a warming tendency over the Nordic Seas. This warming is not significant or evident in MPI-ESM and BCM2, but it is consistent in IPSLCM5, HadCM3, and EC-Earth. As previously noted, this is due to the local SST increase and the associated sea ice response that amplifies the signal in the atmosphere through the albedo feedback. This warming over the Nordic Seas extends over the neighboring landmass, particularly Scandinavia. Such a response remains surprising, but it is 
Fig. 10 Polar view of the annual mean sea ice cover fraction differences between hosing and control experiments averaged over the 4th decade. The contour interval is 0.04 (the sea ice cover being between 0 for no sea ice cover and 1 for closed sea ice cover). a HadCM3, b IPSLCM5, c MPI-ESM, d EC-Earth, e BCM2 and $\mathbf{f}$ ORCA05

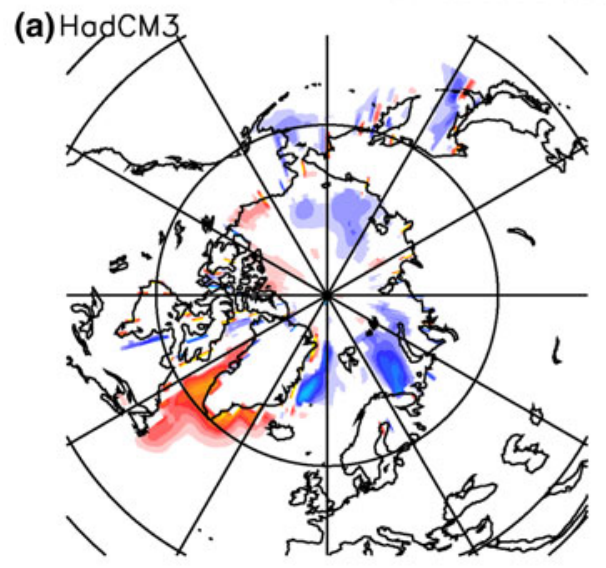

4th decode seo ice cover anomalies

(c) $\mathrm{MP}$

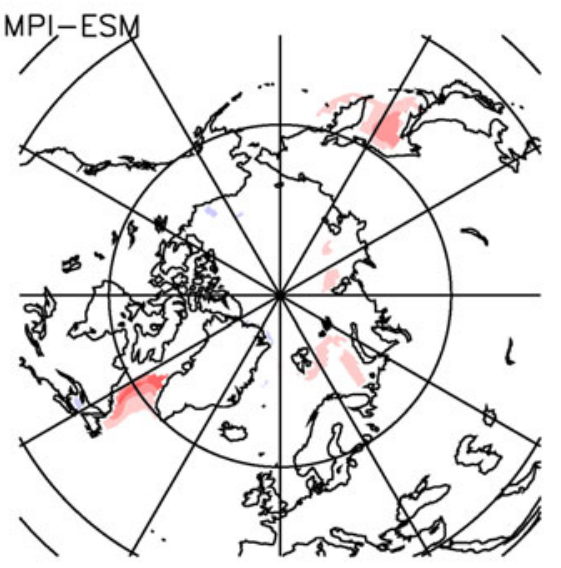

(e)

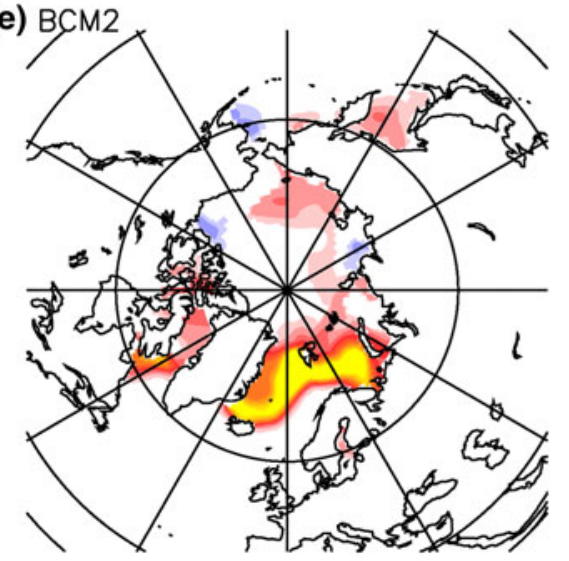

(b)

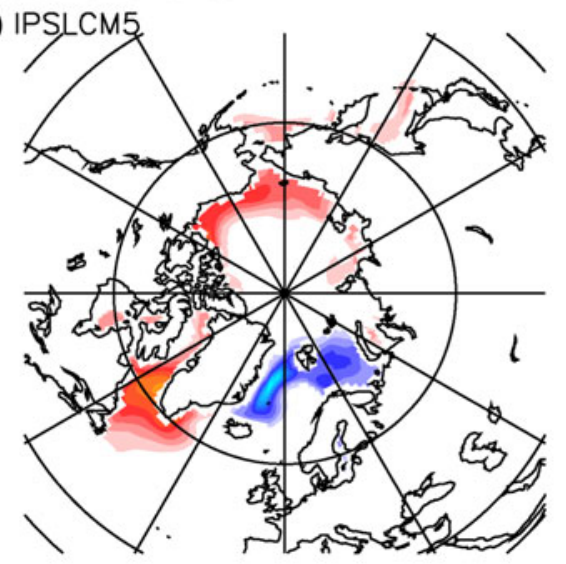

(d)

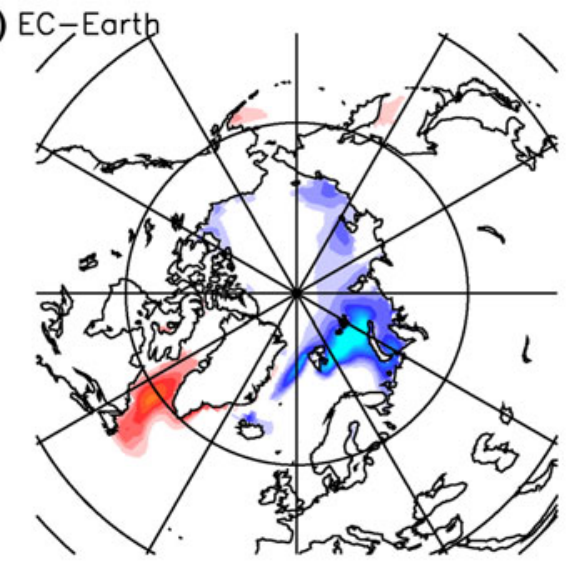

(f)

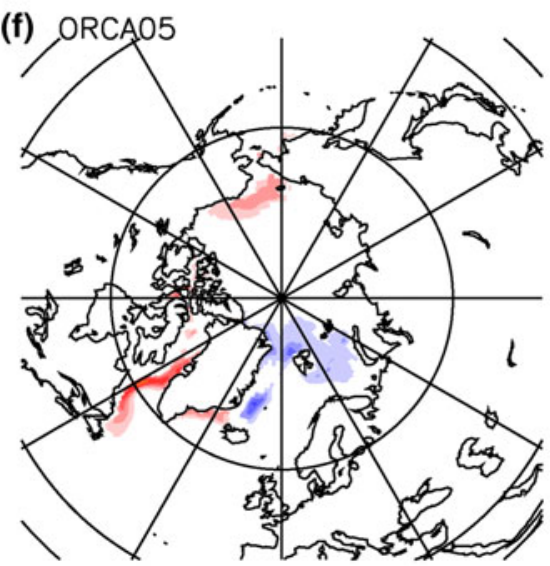

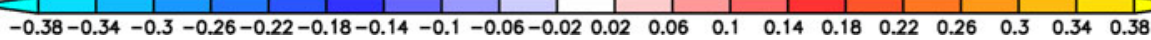

consistent across four of the five climate models and has been found in other models in response to additional freshwater forcing at varying locations (Saenko et al. 2007; Kleinen et al. 2009). Positive surface air temperature anomalies in the Nordic Seas are also found in five models out of fifteen in Fig. 4 of Stouffer et al. (2006).

A potential important impact of AMOC changes is related to the precipitation regimes in the tropical Atlantic (Peterson et al. 2000). A southward shift in the inter- tropical convergence zone (ITCZ) has been found in OAGCMs after a large weakening of the AMOC (Manabe and Stouffer 1988; Schiller et al. 1997; Chiang and Bitz 2005; Swingedouw et al. 2009; Menary et al. 2012). After four decades of increased freshening, we notice a significant weakening of precipitation between 5 and $10^{\circ} \mathrm{N}$ in the Atlantic in four models (Fig. 15). The associated increase south of $5^{\circ} \mathrm{N}$ is less clear in most of the models, maybe because the migration is more diffuse and not yet 
Fig. 11 Temperature $\left(\right.$ in $\left.{ }^{\circ} \mathrm{C}\right)$ in the first $1,000 \mathrm{~m}$ in the Arctic averaged over the region $85^{\circ} \mathrm{N}-$ $90^{\circ} \mathrm{N}$ to $90^{\circ} \mathrm{W}-270^{\circ} \mathrm{W}$. In black is the control simulation, in red the hosing simulation and in grey is the data from Levitus et al. (1998). a HadCM3, b IPSLCM5, c MPI-ESM, d EC-Earth, e BCM2 and f ORCA05

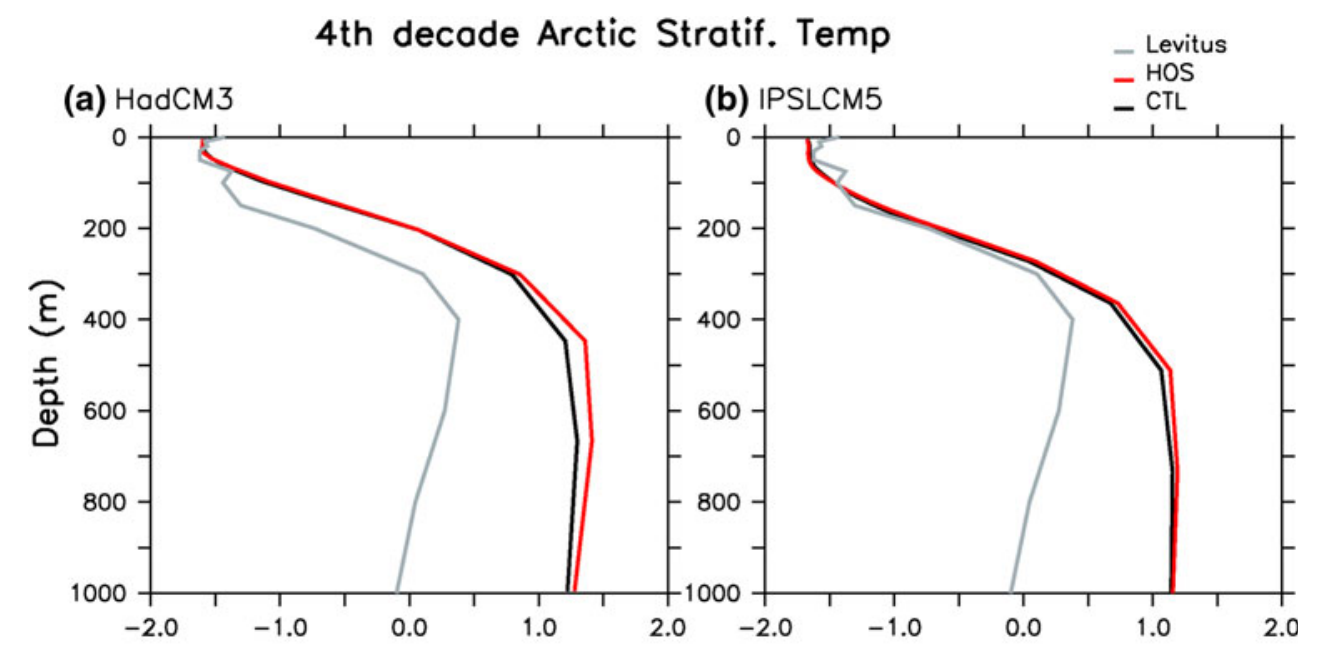

(c) MPI-ESM

(d) EC-Earth

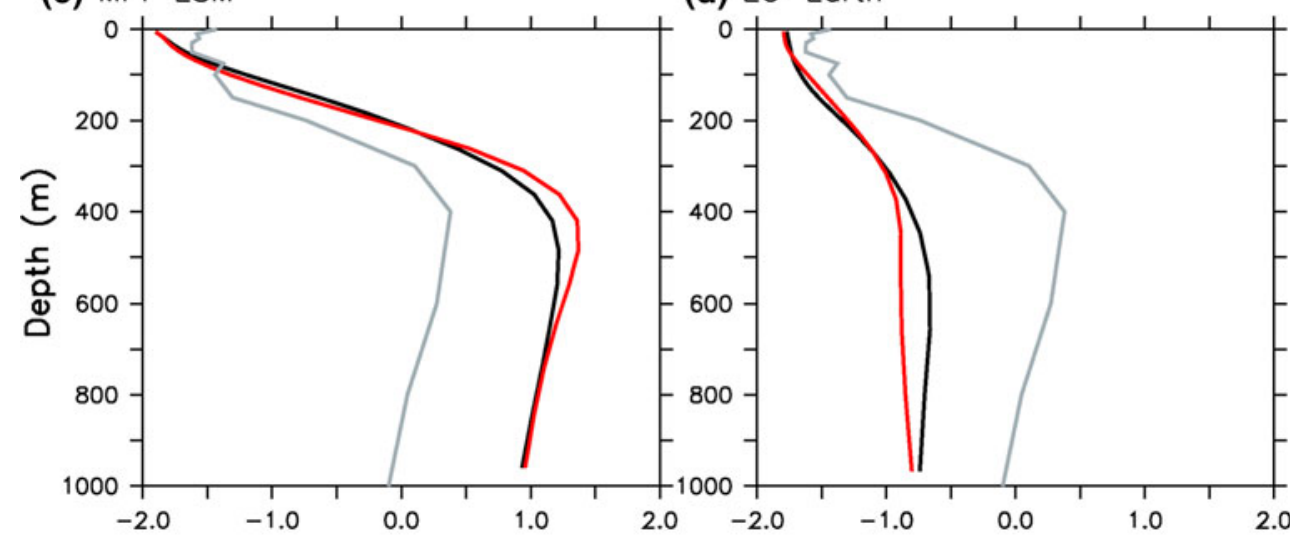

(f) ORCA05

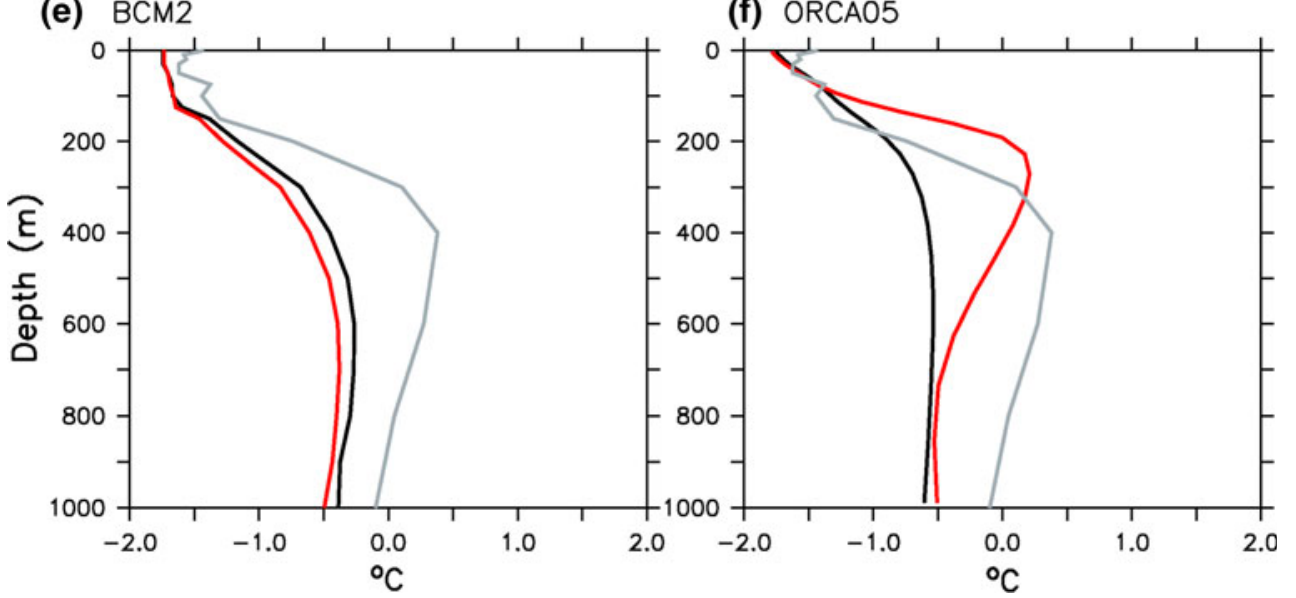

significant everywhere. Also, the AMOC and associated SST response is indeed much weaker than in the previous studies with a different set-up.

\subsubsection{Sea-level fingerprint}

Changes in the AMOC affect the dynamic sea level through the modification of the structure of the main currents. This effect has been illustrated in an intermediate complexity model by Levermann et al. (2005) and can reach $1 \mathrm{~m}$ of regional dynamic sea level for a collapsed AMOC. This sea level change does not account for any effect of freshwater input due to change in the amount of water in the ocean, as well as any effect of the diabatic heating, but only of dynamical changes in the oceanic currents (Lorbacher et al. 2010). In order to 
Fig. 12 Polar view of the annual mean SSS differences between hosing and control experiments averaged over the 4th decade. The contour interval is 0.2 PSU. a HadCM3, b IPSLCM5, c MPI-ESM, d EC-Earth, e BCM2 and f ORCA0 5 (a)

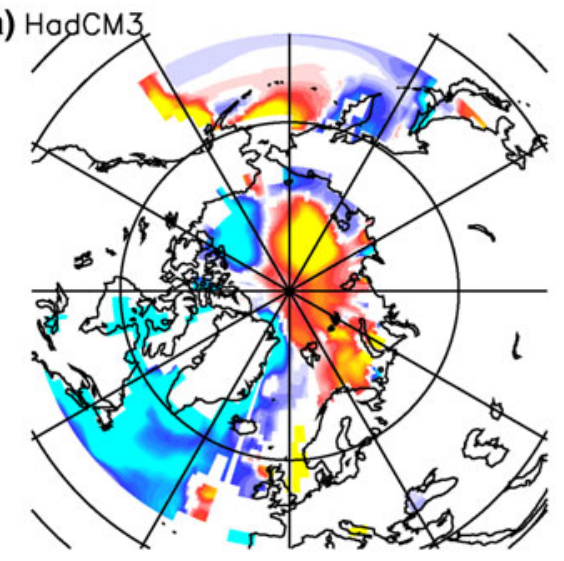

(c)

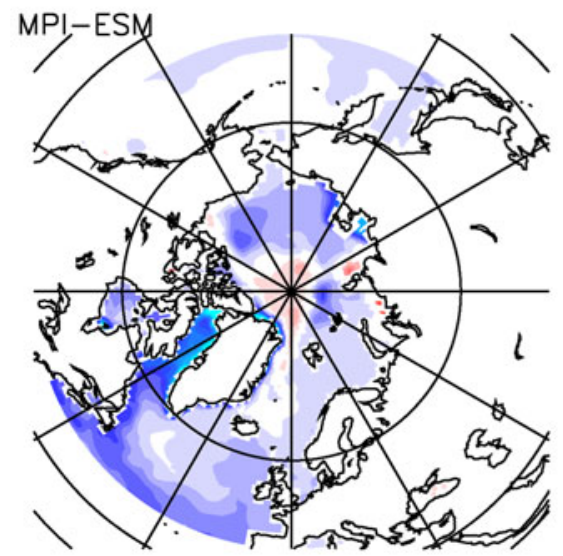

(e)

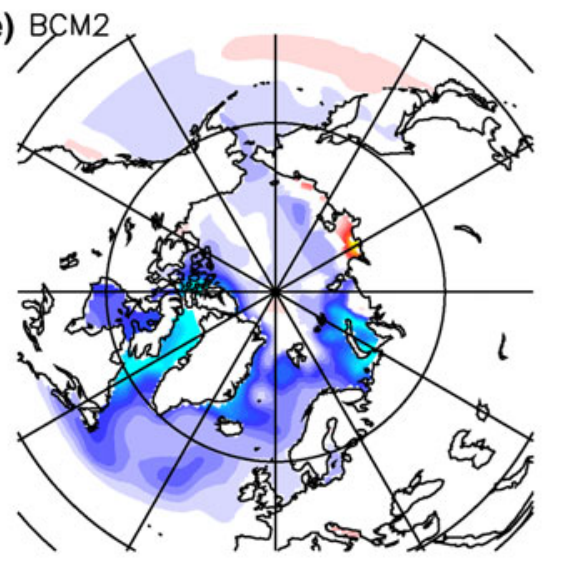

SSS onomalies

(b)

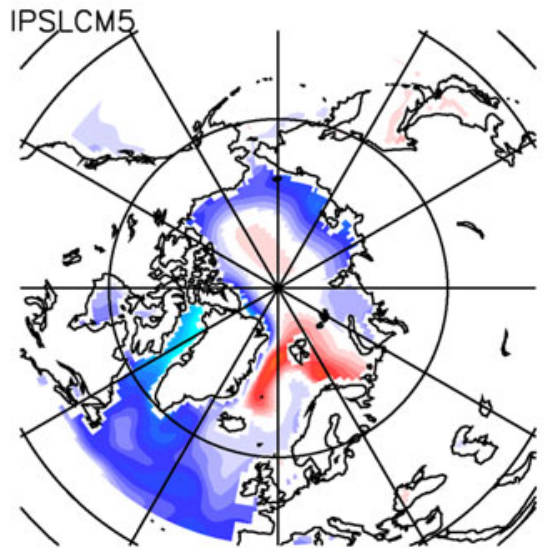

(d)

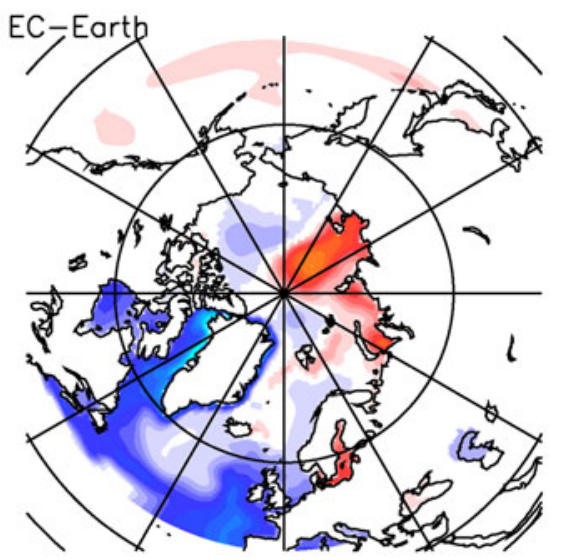

(f)

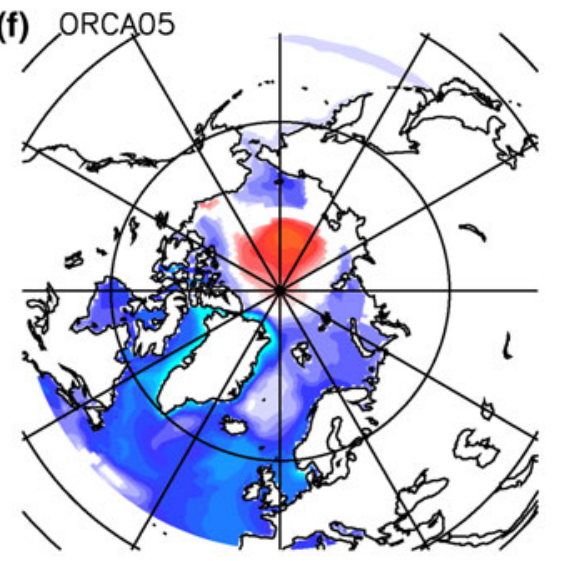

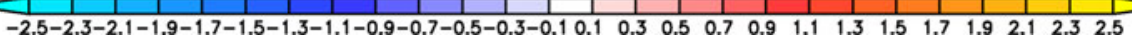

capture also the dynamical effect, the ocean model needs to have a free surface parameterization (Roullet and Madec 2000). In our models ensemble, four (NEMO family and MIP-ESM) out of six use such a parameterization, which offers a way to evaluate the dynamic signatures of the freshwater input around Greenland. In our experimental design, as opposed to Levermann et al. (2005), we account for both the eustatic, as well as the steric contribution to the sea level signature, in addition to the purely dynamical signal.
The increase in sea-level rise in the fourth decade of freshwater input is shown in Fig. 16 for the four models using a free surface parameterization. All models show a general increase in sea level height over the North Atlantic, which is the direct result of the additional water from the hosing. This freshwater input is equal to about $35 \mathrm{~cm}$ of eustatic sea-level rise globally at the end of the simulation. On top of this general rise, we also notice a common structure in the different models, with a maximum sealevel rise around $45^{\circ} \mathrm{N}-30^{\circ} \mathrm{W}$ and a larger sea-level rise 
Fig. 13 Salinity (in PSU) in the first $1,000 \mathrm{~m}$ in the Arctic averaged over the region $85^{\circ} \mathrm{N}-$ $90^{\circ} \mathrm{N}$ to $90^{\circ} \mathrm{W}-270^{\circ} \mathrm{W}$. In black is the control simulation, in red the hosing simulation and in grey is the data from Levitus et al. (1998). a HadCM3, b IPSLCM5, c MPI-ESM, d EC-Earth, e BCM2 and f ORCA05 4th decade Arctic Stratif. Salt

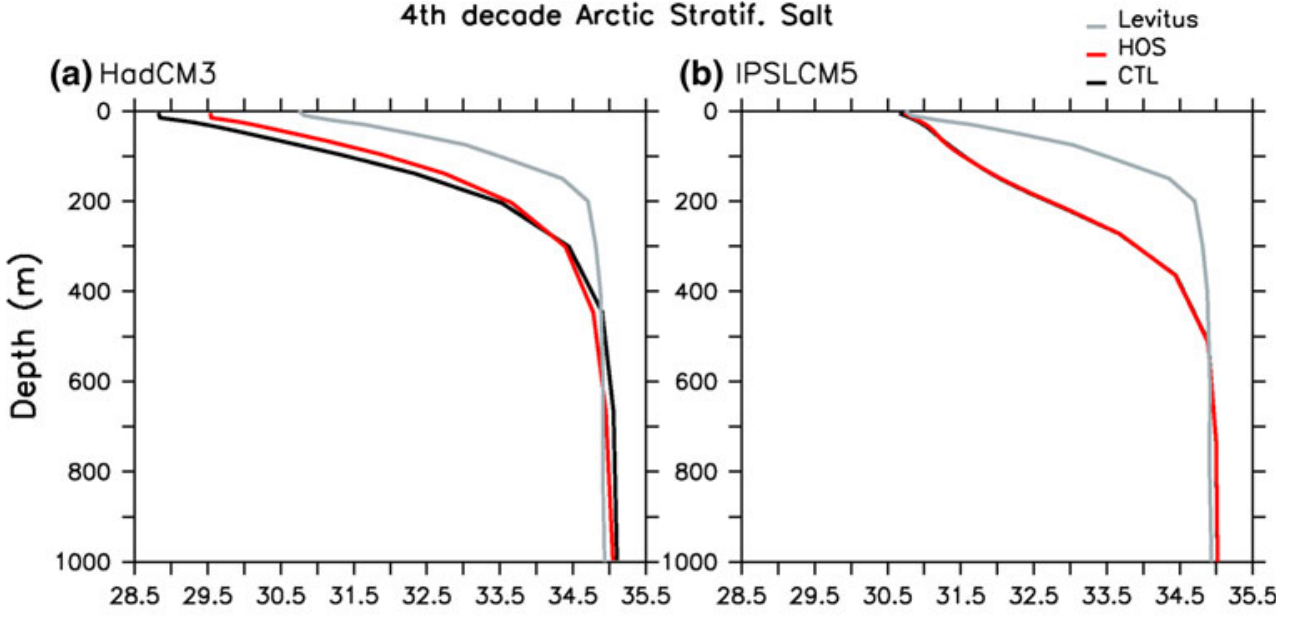

(c) MPI-ESM

(d) EC-Earth

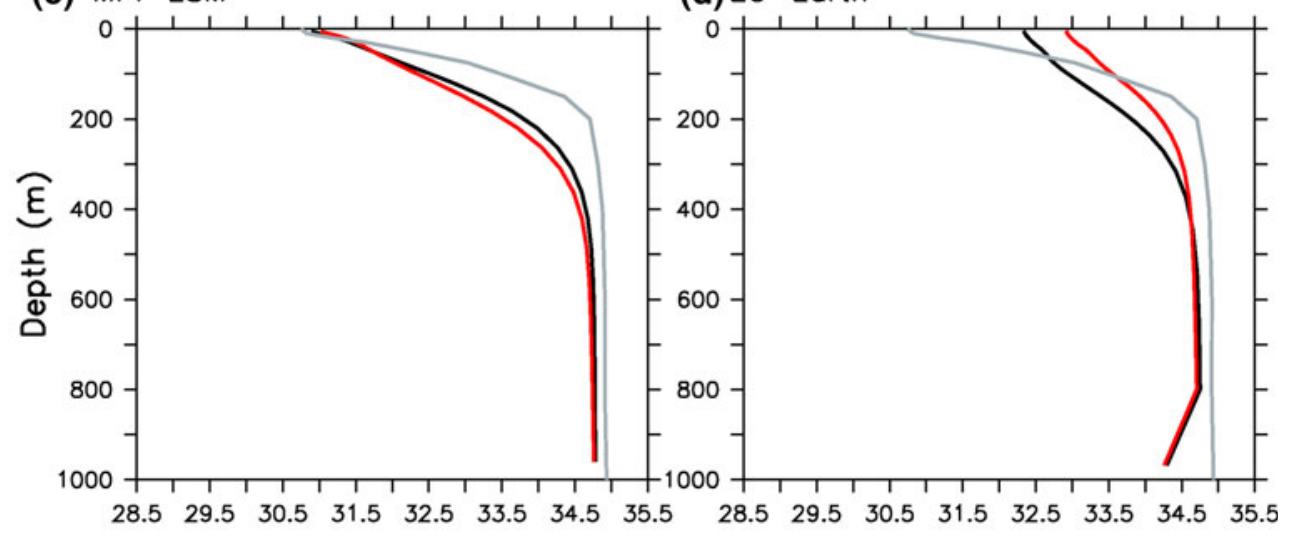

(e) $\mathrm{BCM} 2$

(f) ORCA05

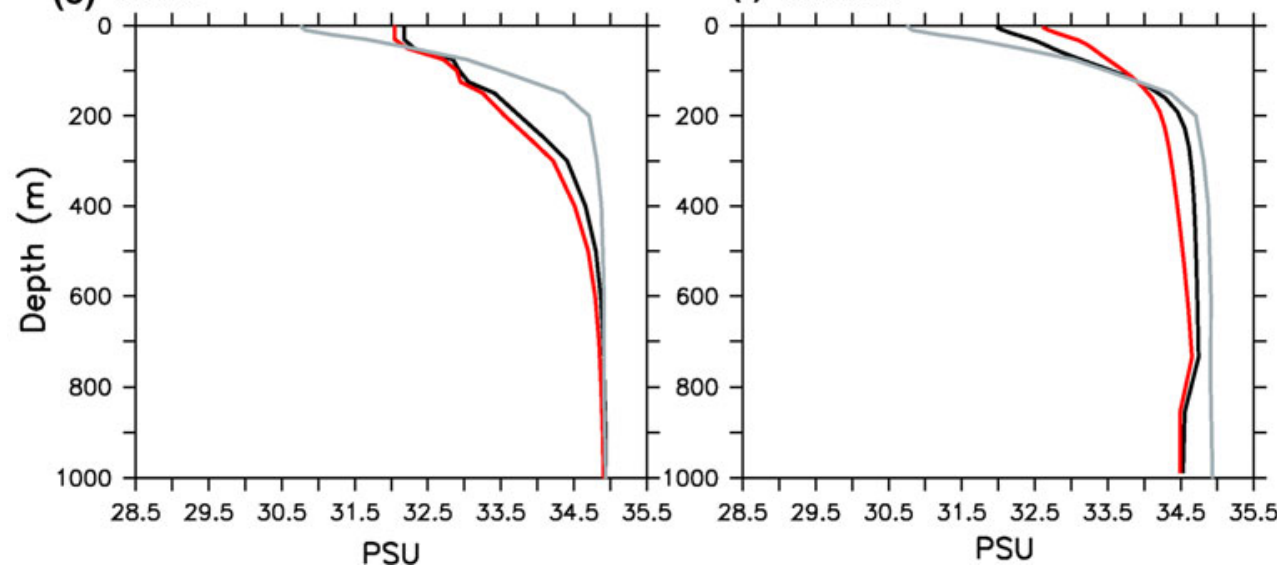

along the west coast of Africa, again following the comma shape of our so-called freshwater leakage. Like in other quantities, the uncoupled ORCA05 shows the largest response in sea level at this location.

It should be pointed out that this sea-level rise response does not account for the changes in mass attraction due to ice sheet mass loss, which, in case of GrIS melting as mimicked here, may ultimately attract less seawater, leading to a regional modulation of the sea level in the
North Atlantic (Mitrovica et al. 2001; Kopp et al. 2010). This effect is not taken into account in any models but is likely negligible for a total ice mass loss of less than $5 \%$.

The patterns of sea-level rise resembles findings from Stammer (2008, Fig. 6) in response to freshwater input around Greenland including a minimum around $60^{\circ} \mathrm{N}-$ $40^{\circ} \mathrm{W}$. However, the comma shape pattern is less clear in his model and the maximum around $45^{\circ} \mathrm{N}-30^{\circ} \mathrm{W}$ is located further east. These characteristics are also different from 
Fig. 14 Map of the atmospheric 2-m temperature difference between hosing and control experiments averaged over the 4th decade. The contour interval is $0.1^{\circ} \mathrm{C}$. a HadCM3, b IPSLCM5, c MPI-ESM, d EC-Earth and e BCM2

\section{4th decode $2 \mathrm{~m}$ temperature anomalies}

(a) $\mathrm{HadCM} 3$

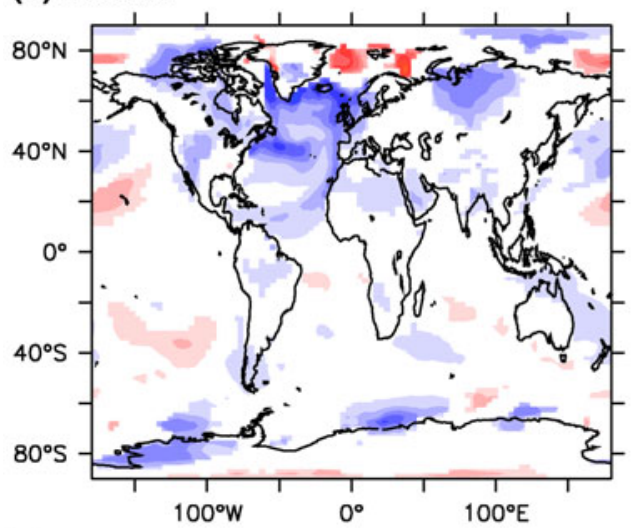

(c) MPI-ESM

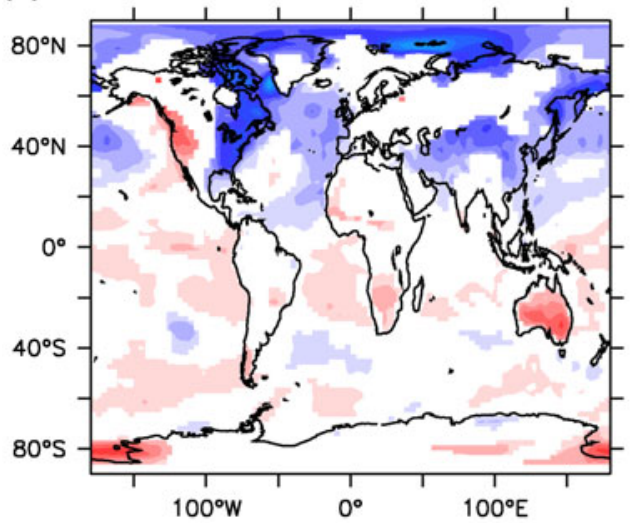

(e) $\mathrm{BCM} 2$

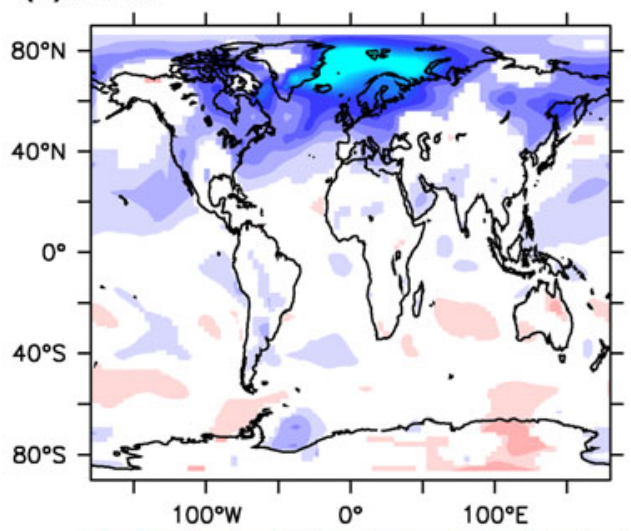

(b) IPSLCM5

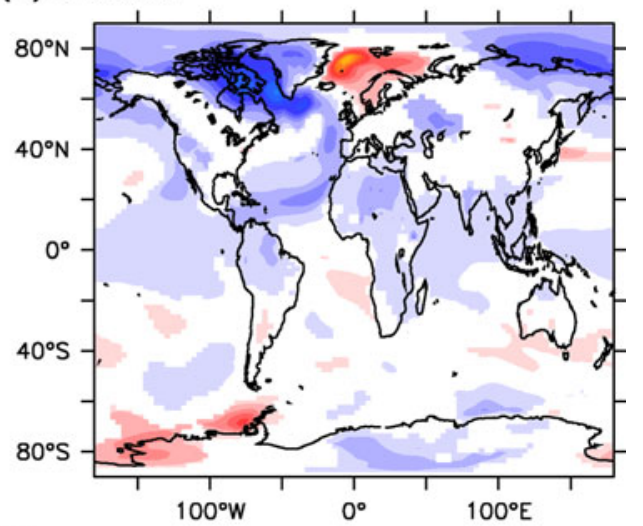

(d) EC-Earth

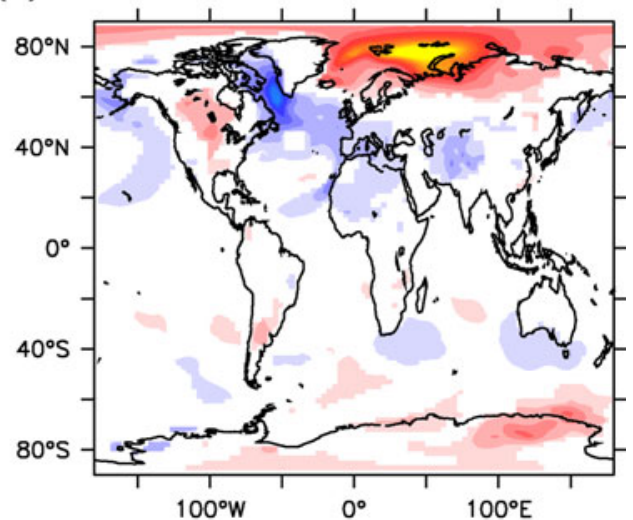

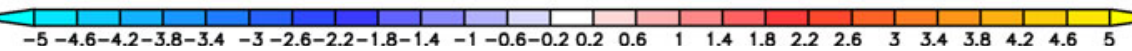

what has been proposed previously as signatures of changes in the AMOC (Zhang 2008; Msadek et al. 2010). Nevertheless, we analyze here the signature of freshwater input, which includes an AMOC response as well as other oceanic adjustment related to the freshwater spread in the Atlantic. This multi-model ensemble therefore provides modeling evidence of the potential spatial fingerprint related to a freshwater input around Greenland, which will help to detect any large-scale change in sea level height in the real ocean in the coming decades. Indeed, we notice on
Fig. 3 from Cazenave and Remy (2011) a larger sea-level rise trend observed for the last 18 years in the eastern part of the subtropical gyre than in the western part, similar to the comma-shape signal discussed earlier.

\section{Discussions and conclusions}

In this study we have analyzed the fingerprints of a continuous $0.1 \mathrm{~Sv}$ freshwater release around the Greenland's 
Fig. 15 Map of the precipitation difference between hosing and control experiments averaged over the 4 th decade.

The contour interval is $0.1 \mathrm{~mm} /$ day. a HadCM3, b IPSLCM5, c MPI-ESM, d EC-Earth and e $\mathrm{BCM} 2$

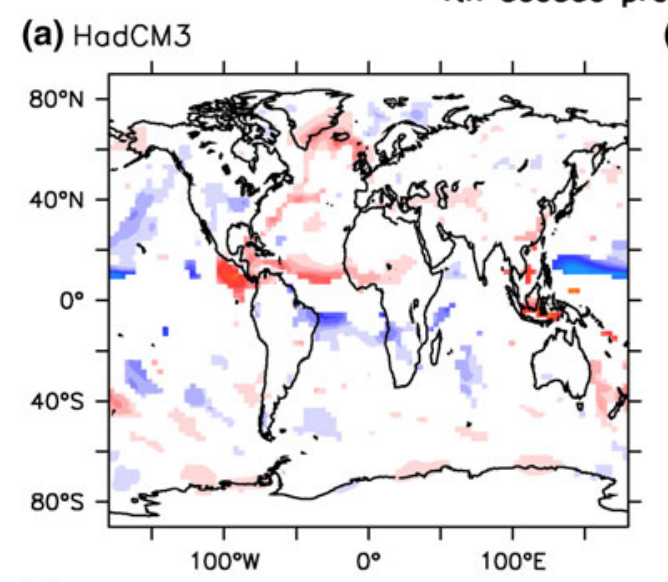

4th decode precip. onomalies

(b) IPSLCM5

(c) MPI-ESM

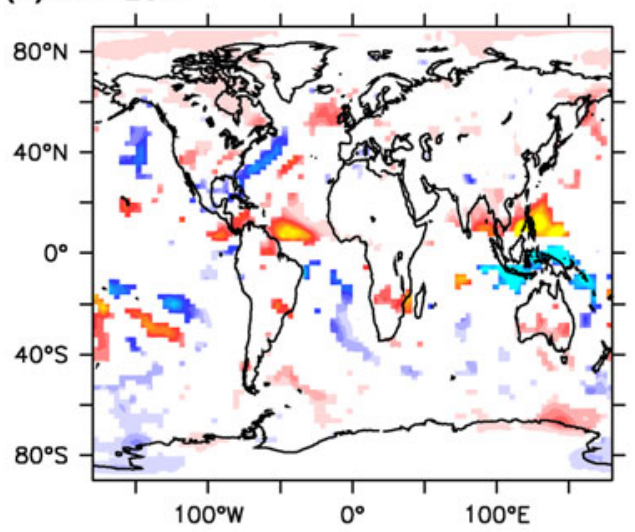

(d) EC-Earth
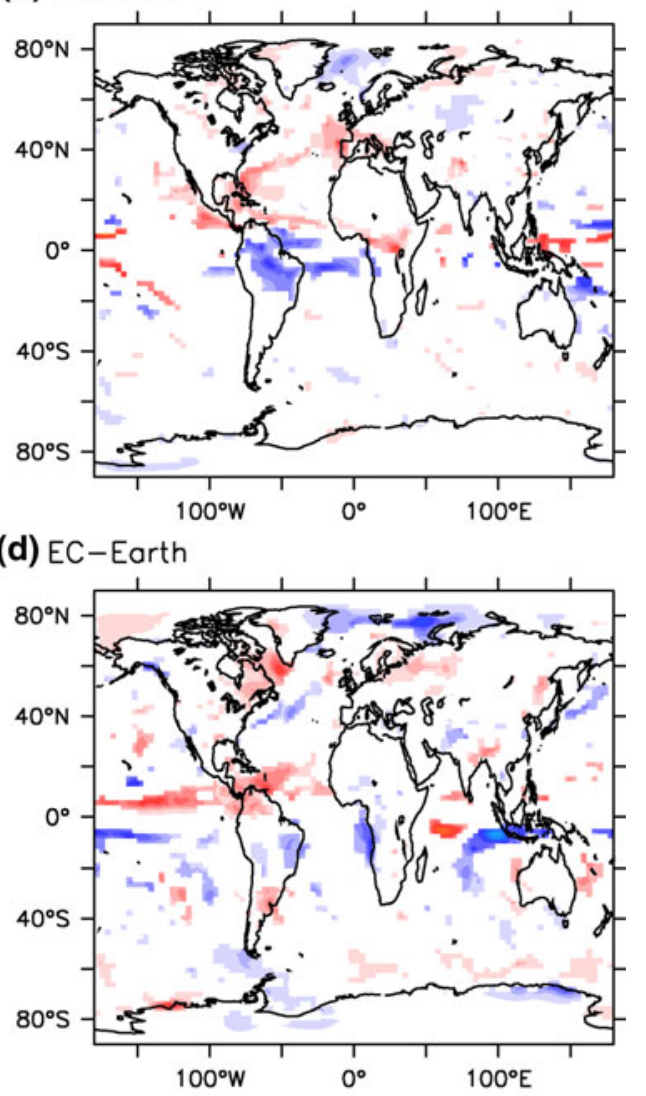

(e) BCM2

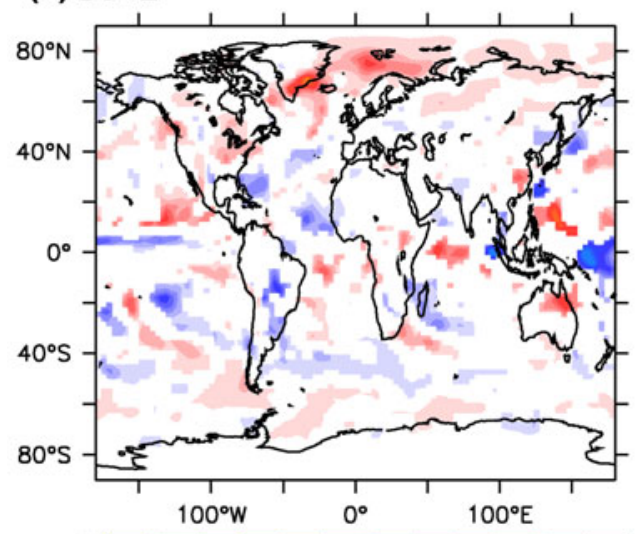

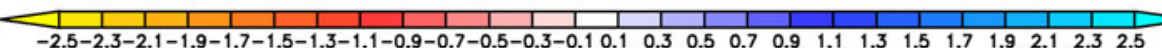

coast over four decades in five coupled climate models and one ocean-only model. The spread of the freshwater input in the different models follows the main currents in each model. The most distinct negative SSS anomaly associated with the freshwater input was found around Greenland. From there it stretches out into the subpolar gyre following the general circulation. In five out of six models a leakage of this freshwater anomaly out of the subpolar North Atlantic could be identified along the Canary Current. On the contrary, the Nordic Seas and the Arctic Ocean did not exhibit basin-wide negative SSS anomalies in most of the models. Patterns of SST anomalies largely mirror SSS anomalies whereby a freshening often corresponds to a cooling. Furthermore, a surprising pattern of warming in the Nordic Seas is found in five out of six models including the ocean-only model. We explain this by the emergence of Atlantic subsurface water masses that are not influenced by mixed layer water mass intrusion in the subpolar gyre due to the capping of the surface by freshwater. This Atlantic water mass enters the Nordic Seas where it emerges partly 
Fig. 16 Map of the sea level height difference between hosing and control experiments averaged over the 4 th decade.

The contour interval is $5 \mathrm{~cm}$. a IPSLCM5, b MPI-ESM, c ECEarth and d ORCA05

\section{4th decade SSH anomalies}

(a) IPSLCM5

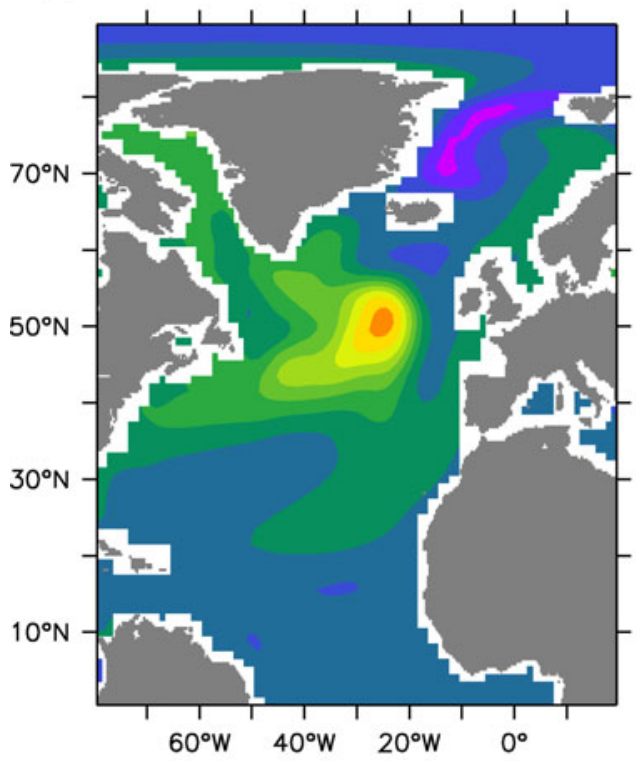

(c) EC-Earth

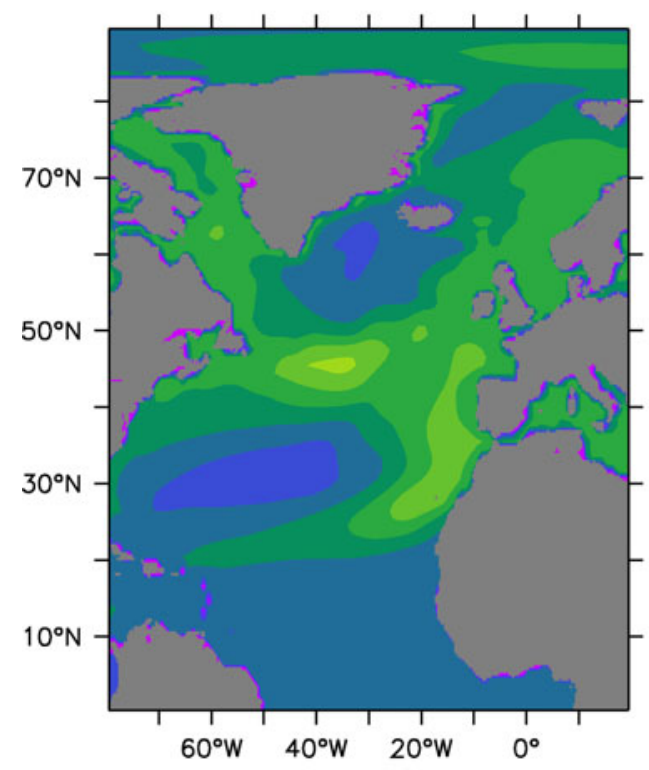

(b) MPI-ESM

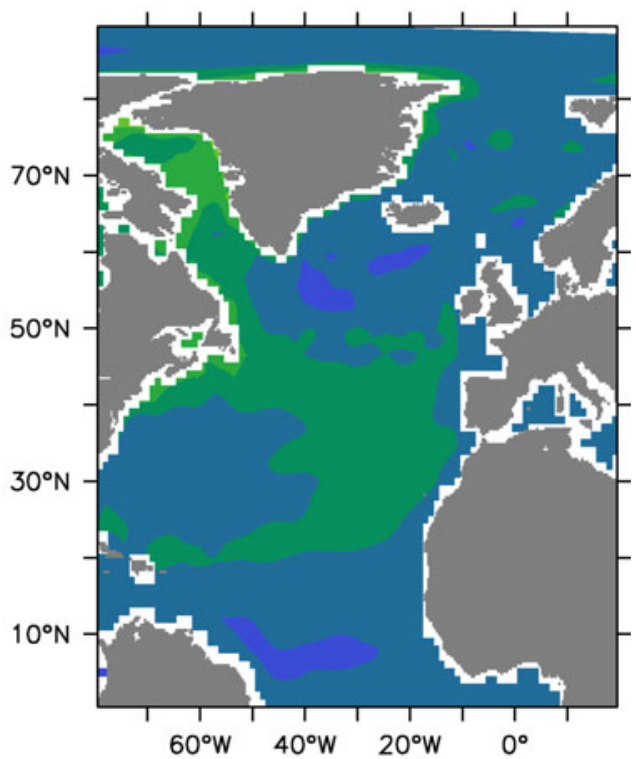

(d) ORCAO5

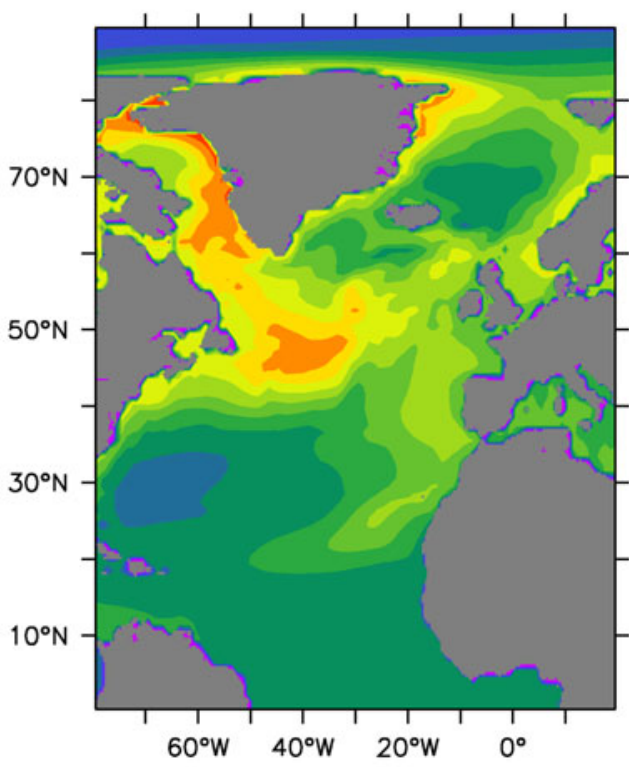

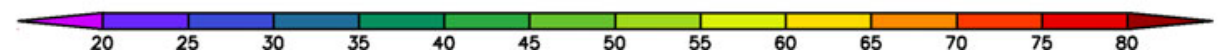

while the rest continues to the Arctic, with different hydrological characteristics due to mixing with fresher water. There it contributes to the positive SSS anomaly in the vicinity of the North Pole that is detected in all the models.

In all the models the convective activity in the North Atlantic, as measured by the maximum mixed layer depth, decreases in response to the additional freshwater input, although the weakening in the AMOC is not significant in all the models. We suggest that this difference in sensitivity across the model ensemble is due to differences in the magnitude of the freshwater leakage: the larger the amount of freshwater that escapes in the subtropical Atlantic, the smaller the decrease of SSS and convection in the subpolar gyre. As a consequence, the AMOC weakening is limited in models with a large leakage such as HadCM3 and MPIESM. We found that the magnitude of the leakage itself is linked with the mean shape of the barotropic stream function, namely the meridional tilt of the separation between the two gyres: the stronger this tilt, the weaker the 
leakage. The strength of the subpolar gyre exhibits a weakening in only a subset of models, while the subtropical gyre is hardly affected in any model.

We have analyzed the climatic imprints linked to enhanced GrIS melting in terms of surface temperature, precipitations and sea-level signatures. These are key metrics in the context of climate change. The atmospheric surface temperature concurs with the SST showing a large cooling over the subpolar gyre and along the Canary Current. We find a surprising warming in five out of six models in the Nordics Seas associated with the SST increase. This is enhanced in the climate models by the associated retreat of sea ice and the albedo feedback. This has important implications for the uncertainty of the temperature response over Northern Europe. Significant temperature anomalies are also found over the northeastern coast of the American continent, but their sign is not robust across the models. Beyond the Atlantic surroundings, no significant temperature anomalies are detected over land. We find hints of a slight southward shift of the ITCZ in most of the models after four decades of freshwater input, pointing to the robustness of such a modification of the tropical precipitation regime in response to GrIS disintegration. Such a shift could have serious consequences for regional adaptation strategies in response to global warming. Sea-level rise was found to be highly inhomogeneous in space, with large changes in the steric and dynamic sealevel components, the latter related to changes in the mean ocean currents. Patterns were similar in all the models using a free surface formulation and seem therefore a robust fingerprint of the GrIS disintegration, which needs to be properly taken into account in sea-level rise adaptation strategy. Such a signature could also be useful in detecting any sea-level changes related to the accelerated ice mass loss in Greenland.

For most of the different fingerprints discussed in this study, BCM2 often showed a unique response (e.g. freshwater leakage, Arctic SSS positive anomaly, Nordic Seas warming). This model is the only one formulated entirely on isopycnal coordinates. As these fingerprints are clearly not independent metrics, it may be expected that model flaws in one region may ultimately explain a number of these differences. One candidate is clearly the effective and likely unrealistic mixing of freshwater from the East Greenland Current into the central gyres of the Nordic Seas in BCM2, linked to limited grid resolution in the region of the Denmark Strait. This indicates that details of the ocean component of the coupled climate models may be deterministic for the model response to our additional freshwater forcing for the period of four decades. This idea is also supported by the fact that the ocean-only model used in this study shares important similarities with the climate models. In other words, it implies that the similar fingerprints found among the models in response to a freshwater input around Greenland are mainly related to oceanic processes. Nevertheless, the coupling with the atmosphere, which in general is believed to have a stabilizing effect on the deep water formation, may explain the differences in the magnitude of the these fingerprints and the generally stronger response of the ocean-only model.

The warming in the Nordic Seas is an intriguing pattern of response to freshwater input in the North Atlantic. It confirms that the responses do not simply cool the entire North Atlantic region, as suggested by other studies (e.g. Stouffer et al. 2006; Saenko et al. 2007). The mechanism by which this pattern is explained is related to subsurface intrusion and emergence of Atlantic water, similar to what Mignot et al. (2007) proposed as a response to a collapse of the AMOC.

The freshwater leakage may be important for the AMOC response and it is linked to the exchange between the subpolar and subtropical gyres. We propose that the intensity of the freshwater leakage is related to the shape of the gyres and in particular the boundary slope between the subpolar and subtropical gyres. We find a significant relationship between this asymmetry and the AMOC weakening in the different models. We argue that the differences in the asymmetry among the models can be related to different resolution (vertical in particular, see Shimokawa and Matsuura 1999), parameterization in the ocean physics as well as different wind stress forcing. Condron and Winsor (2011) found a similar freshwater leakage path in a high resolution OGCM $\left(1 / 6^{\circ}\right.$, see their Fig. 1), indicating that this pattern is robust even in a higher resolution eddy permitting model. Recent observations of the gyre asymmetry in the Atlantic from Rypina et al. (2011) indicate a boundary between subpolar and subtropical gyres with a slope similar to the one found in ORCA05 or BCM2, which exhibit the largest inter-gyre tilt and the largest AMOC weakening. If the relationship between AMOC response and gyre asymmetry holds in the real world, this may indicate a larger AMOC sensitivity to GrIS melting in the real world than in most current AOGCMs, which exhibit large biases in this gyre asymmetry.

As compared to the sensitivity experiments from Stouffer et al. (2006), our experiments are shorter and the freshwater input is restricted to the coast of Greenland in contrast to a homogeneous release over a wide band between $50^{\circ}$ and $70^{\circ} \mathrm{N}$. This allows a more realistic evaluation of the impact of a freshwater input from the runoff of GrIS melting on the North Atlantic and a more precise circulation of the anomalies-leading to interesting effects like the freshwater leakage that emerges through the mean oceanic circulation. The Stouffer et al. (2006) experimental 
design may have diluted such an effect through the large extent of the freshwater input.

Nevertheless, in the Stouffer et al. (2006) study, HadCM3 and ECHAM5/MPI-OM (the former version of MPIESM) were found to have a relatively small sensitivity of the AMOC to the freshwater input (about 1 and $3 \mathrm{~Sv}$ of decrease after 40 years in HadCM3 and ECHAM5/MPIOM respectively, while the mean response of the different models was around $4 \mathrm{~Sv}$ at that time). This lower sensitivity is confirmed here. We argue that an important mechanism to explain such a low sensitivity is the capacity of these models to export freshwater towards the subtropics (freshwater leakage). This is related to the shape of the mean oceanic circulation. The AMOC in IPSLCM5 (as well as in IPSLCM4, see Swingedouw et al. 2009) is more sensitive to a freshwater anomaly than HadCM3 and ECHAM5/MPI-OM. This is interesting given the different conclusions drawn by these different models in the projections with a GrIS melting: while HadCM3 (Ridley et al. 2005) and ECHAM5/MPI-OM (Jungclaus et al. 2006; Mikolajewicz et al. 2007) found a slight influence of the freshwater input from GrIS melting on the AMOC in projections, IPSLCM4, the former version of IPSLCM5, found a larger sensitivity (Swingedouw et al. 2007). It seems that we can explain part of this difference by the different sensitivity of these models to freshwater input (and ultimately at least partly to the inter-gyre geometry).

The weak intensity of the AMOC in IPSLCM4 (and IPSLCM5) is clearly not the only explanation for this difference of sensitivity between the former models, since EC-Earth or BCM2 show large sensitivity to freshwater input despite having a stronger mean state for the AMOC. We could not identify any clear relationship between the mean state of the AMOC and the sensitivity to freshwater input around Greenland. Moreover, we can hypothesize that EC-Earth or BCM2 may exhibit very large sensitivity (in agreement with ORCA05, the highest resolution ocean model of the ensemble) to such large GrIS melting in projections. The next step is to implement projections with an additional $0.1 \mathrm{~Sv}$ around Greenland from the year 2050 within the different models analyzed here in order to provide an assessment of the climatic impacts of enhanced GrIS melting under evolving climate conditions with emphasis on climate stability.

Acknowledgments The research leading to these results has received funding from the European Union's Seventh Framework Programme (FP7/2007-2013) under grant agreement no 212643 (THOR). DS and JM also acknowledge financial support from the CNRS/INSU/LEFE/EVE French program through the Ti Ammo project. CR performed these simulations at the German Climate Computing Centre (DKRZ), Hamburg. DS and JM benefited of the HPC resources of CCRT and IDRIS made available by GENCI (Grand Equipement National de Calcul Intensif).

\section{References}

Biastoch A, Böning CW, Getzlaff J, Molines J-M, Madec G (2008) Mechanisms of interannual-decadal variability in the meridional overturning circulation of the mid-latitude North Atlantic Ocean. J Clim 21:6599-6615. doi:10.1175/2008JCLI2404.1

Blanke B, Delecluse P (1993) Variability of the tropical Atlantic Ocean simulated by a general circulation model with two different mixed layer physics. J Phys Oceanogr 23:1363-1388

Böning CW, Scheinert M, Dengg J, Biastoch A, Funk A (2006) Decadal variability of subpolar gyre transport and its reverberation in the North Atlantic overturning. Geophys Res Lett 33(21):1-5. doi:10.1029/2006GL026906

Bryan F (1987) Parameter sensitivity of primitive equation ocean general circulation models. J Phys Oceanogr 17:970-985

Bryden HL, Longworth HR, Cunningham SA (2005) Slowing of the Atlantic meridional overturning circulation at $25^{\circ} \mathrm{N}$. Nature 438:655-657

Cazenave A, Remy F (2011) Sea level and climate: measurements and causes of changes. Wiley Interdiscip Rev 2:647-662. doi: $10.1002 /$ wcc. 139

Chiang JCH, Bitz CM (2005) Influence of high latitude ice cover on the marine Intertropical Convergence Zone. Clim Dyn 25:477-496

Christoffersen P, Mugford RI, Heywood KJ, Joughin I, Dowdeswell JA, Syvitski JPM, Luckman A, Benham TJ (2011) Warming of waters in an East Greenland fjord prior to glacier retreat: mechanisms and connection to large-scale atmospheric conditions. Cryosphere 5(3):701-714. doi:10.5194/tc-5-701-2011

Clement AC, Peterson LC (2008) Mechanisms of abrupt climate change of the last glacial period. Rev Geophys 46:RG4002. doi: 10.1029/2006RG000204

Condron A, Winsor P (2011) A subtropical fate awaited fresh water discharged from glacial Lake Agassiz. Geophys Res Lett 38:L03705. doi:10.1029/2010GL046011

Crowley TJ (1992) North Atlantic deep waters cools the Southern Hemisphere. Paleoceanography 7:489-497

Driesschaert E, Fichefet T, Goosse H, Huybrechts P, Janssens I, Mouchet A, Munhoven G, Brovkin V, Weber SL (2007) Modelling the influence of Greenland ice sheet melting on the Atlantic meridional overturning circulation during the next millennia. Geophys Res Lett 34:L1070

Dufresne J-L, Foujols M-A, Denvil S, Caubel A, Marti O, Aumont O, Balkanski Y, Bekki S, Bellenger H, Benshila R, Bony S, Bopp L, Braconnot P, Brockmann P, Cadule P, Cheruy F, Codron F, Cozic A, Cugnet D, de Noblet N, Duvel J-P, Ethé C, Fairhead L, Fichefet T, Flavoni S, Friedlingstein P, Grandpeix J-Y, Guez L, Guilyardi E, Hauglustaine D, Hourdin F, Idelkadi, Ghattas J, Joussaume S, Kageyama M, Krinner G, Labetoulle S, Lahellec A, Lefebvre M-P, Lefevre F, Levy C, Li ZX., Lloyd J, Lott F, Madec G, Mancip M, Marchand M, Masson S, Meurdesoif Y, Mignot J, Musat I, Parouty S, Polcher J, Rio C, Schulz M, Swingedouw D, Szopa S, Talandier C, Terray P, Viovy N (submitted) Climate change projections using the IPSL-CM5 earth system model: from CMIP3 to CMIP5. Clim Dyn

Fedoseev A (1970) Geostrophic circulation of surface waters on the shelf of north-west Africa. Rapp P-V Reun Cons Int Explor Mer 159:32-37

Frankignoul C, Deshayes J, Curry R (2009) The role of salinity in the decadal variability of the North Atlantic meridional overturning circulation. Clim Dyn. doi:10.1007/s00382-008-0523-2

Gaspar P (1988) Modelling the seasonal cycle of the upper ocean, 1. Phys Oceanogr 18:161-180

Gerdes R, Hurlin W, Griffies SM (2006) Sensitivity of a global ocean model to increased run-off from Greenland. Ocean Model 
12(3-4):416-435. ISSN:1463-5003, doi:10.1016/j.ocemod.2005. 08.003

Gordon C, Cooper C, Senior CA, Banks H, Gregory JM, Johns TC, Mitchell JFB, Wood RA (2000) The simulation of SST, sea ice extents and ocean heat transports in a version of the Hadley Centre coupled model without flux adjustments. Clim Dyn $16: 147-168$

Gregory JM, Tailleux R (2011) Kinetic energy analysis of the response of the Atlantic meridional overturning circulation to $\mathrm{CO}_{2}$-forced climate change. Clim Dyn 37:893-914

Greve R (1997) Application of a polythermal three-dimensional ice sheet model to the Greenland ice sheet: response to steady-state and transient climate scenarios. J Clim 10(5):901-918. doi: $10.1175 / 1520-0442$

Greve R, Hutter K, Giu E (1995) Polythermal three-dimensional modelling of the Greenland ice sheet with varied geothermal heat flux. Ann Glaciol 21:8-12

Hawkins E, Smith RS, Allison LC, Gregory JM, Woollings TJ, Pohlmann H, de Cuevas B (2011) Bistability of the Atlantic overturning circulation in a global climate model and links to ocean fresh water transport. Geophys Res Lett 38:L10605. doi: 10.1029/2011GL047208

Heinrich H (1988) Origin and consequences of cyclic ice rafting in the Northeast Atlantic Ocean during the past 130000 years. Quat Res 29:142-152

Holland DM, Thomas RH, de Young B, Ribergaard MH, Lyberth B (2008) Acceleration of Jakobshavn Isbræ triggered by warm subsurface ocean waters. Nat Geosci 1(10):659-664. doi: 10.1038/ngeo316

Hu A, Meehl GA, Han W, Yin J (2011) Effect of the potential melting of the Greenland ice sheet on the meridional overturning circulation and global climate in the future. Deep Sea Res Part II 58(17-18):1914-1926. doi:10.1016/j.dsr2.2010.10.069

Huybrechts P, de Wolde J (1999) The dynamic response of the Greenland and Antarctic ice sheets to multiple-century climatic warming. J Clim 12(8):2169-2188. doi:10.1175/1520-0442

Huybrechts P, Janssens I, Poncin C, Fichefet T (2002) The response of the Greenland ice sheet to climate changes in the 21st century by interactive coupling of an AOGCM with a thermomechanical ice-sheet model. Ann Glaciol 35(1):409-415. doi:10.3189/ 172756402781816537

Johns WE, Shay TJ, Bane JM, Watts DR (1995) Gulf Stream structure, transport and recirculation near $68^{\circ} \mathrm{W}$. J Geophys Res 100:817-838

Jungclaus JH, Haak H, Esch M, Roeckner E, Marotzke J (2006) Will Greenland melting halt the thermohaline circulation? Geophys Res Lett 33, Article Number: L17708

Jungclaus JH, Fischer N, Haak H, Lohmann K, Marotzke J, Matei D, Mikolajewicz U, Notz D, von Storch JS (submitted) Characteristics of the ocean simulations in MPIOM, the ocean component of the MPI-earth system model. J Adv Model Earth Syst

Kageyama M, Paul A, Roche DM, Van Meerbeeck CJ (2010) Modelling glacial climatic millennial-scale variability related to changes in the Atlantic meridional overturning circulation: a review. Quat Sci Rev 29:2931-2956

Kanzow T, Cunningham SA, Johns WE, Hirschi JJ-M, Marotzke J, Baringer MO, Meinen CS, Chidichimo MP, Atkinson C, Beal LM, Bryden HL, Collins J (2010) Seasonal variability of the Atlantic meridional overturning circulation at $26.5^{\circ} \mathrm{N}$. J Clim 23:5678-5698. doi:10.1175/2010JCLI3389.1

Kleinen T, Osborn TJ, Briffa KR (2009) Sensitivity of climate response to variations in fresh water hosing location. Ocean Dyn 59:509-521. doi:10.1007/s10236-009-0189-2

Kopp RE, Mitrovica JX, Griffies SM, Yin J, Hay CC, Stouffer RJ (2010) The impact of Greenland melt on local sea levels: a partially coupled analysis of dynamic and static equilibrium effects in idealized water-hosing experiments. Clim Chang 103(3-4). doi:10.1007/s10584-010-9935-1

Large WG, Yeager SG (2009) The global climatology of an interannually varying air-sea flux data set. Clim Dyn 33:341-364. doi:10.1007/s00382-008-0441-3

Large WG, McWilliams JC, Doney SC (1994) Oceanic vertical mixing: a review and a model with a nonlocal boundary layer parameterization. Rev Geophys 32:363-403. doi:10.1029/ 94RG01872

Levermann A, Born A (2007) Bistability of the Atlantic subpolar gyre in a coarse resolution climate model. Geophys Res Lett 34:L24605

Levermann A, Griesel A, Hofmann M, Montoya M, Rahmstorf S (2005) Dynamic sea level changes following changes in the thermohaline circulation. Clim Dyn 24:347-354

Levitus $S$ et al (1998) Introduction, vol 1. World Ocean Database 1998. NOAA Atlas NESDIS 18, NOAA/NESDIS, U.S. Dept. of Commerce, Washington, DC

Lorbacher K, Dengg J, Böning CW, Biastoch A (2010) Regional patterns of sea level change related to interannual variability and multi-decadal trends in the Atlantic meridional overturning circulation. J Clim 23:4243-4254. doi:10.1175/2010JCLI3341.1

Madec G (2008) NEMO ocean engine. Note du Pole de modélisation, Institut Pierre-Simon Laplace (IPSL), France, No. 27, ISSN:1288-1619

Maier-Reimer E, Mikolajewicz U (1989) Experiments with an OGCM on the cause of the Younger Dryas. MPI Rep 39, Hamburg, Germany

Manabe S, Stouffer RJ (1988) Two stable equilibria of a coupled ocean-atmosphere model. J Clim 1:841-866

Marsh R, Desbruyeres D, Bamber JL, De Cuevas BA, Coward AC, Aksenov Y (2010) Short-term impacts of enhanced Greenland freshwater fluxes in an eddy-permitting ocean model. Ocean Sci 6(3):749-760

Marti O, Braconnot P, Dufresne JL, Bellier J, Benshila R, Bony S, Brockmann P, Cadule P, Caubel A, Codron F, de Noblet N, Denvil S, Fairhead L, Fichefet T, Foujols MA, Friedlingstein P, Goosse H, Grandpeix JY, Guilyardi E, Hourdin F, Idelkadi A, Kageyama M, Krinner G, Lévy C, Madec G, Mignot J, Musat I, Swingedouw D, Talandier C (2010) Key features of the IPSL ocean atmosphere model and its sensitivity to atmospheric resolution. Clim Dyn 34:1-26. doi:10.1007/s00382-009-0640-6

Menary MB, Park W, Lohmann K, Vellinga M, Palmer MD, Latif M, Jungclaus JH (2012) A multimodel comparison of centennial Atlantic meridional overturning circulation variability. Clim Dyn 38:2377-2388. doi:10.1007/s00382-011-1172-4

Mignot J, Frankignoul C (2005) On the variability of the Atlantic meridional overturning circulation, the NAO and the ENSO in the Bergen Climate Model. J Clim 18(13):2361-2375

Mignot J, Frankignoul C (2010) Local and remote impacts of a tropical Atlantic salinity anomaly. Clim Dyn 35(7-8):1133-1147

Mignot J, Ganopolski A, Levermann A (2007) Atlantic subsurface temperatures: response to a shut-down of the overturning circulation and consequences for its recovery. J Clim 20:48844898

Mikolajewicz U, Maier-Reimer E (1994) Mixed boundary conditions in ocean general circulation models and their influence on the stability of the model's conveyor belt. J Geophys Res 99(C11): 22633-22644

Mikolajewicz U, Vizcaíno M, Jungclaus J, Schurgers G (2007) Effect of ice sheet interactions in anthropogenic climate change simulations. Geophys Res Lett 34:L18706. doi:10.1029/2007 GL031173

Mitrovica JX, Tamisiea ME, Davis JL, Milne GA (2001) Recent mass balance of polar ice sheets inferred from patterns of global sealevel change. Nature 409:1026-1029 
Msadek R, Dixon KW, Delworth TL, Hurlin W (2010) Assessing the predictability of the Atlantic meridional overturning circulation and associated fingerprints. Geophys Res Lett 37:L19608. doi: 10.1029/2010GL044517

Nakamura M, Stone PH, Marotzke J (1994) Destabilization of the thermohaline circulation by atmospheric eddy transports. J Clim 7:1870-1882

Otterå OH, Bentsen M, Drange H, Suo L (2010) External 675 forcing as a metronome for Atlantic multidecadal variability. Nat Geosci 3:688-694. doi:10.1038/ngeo955

Pacanowski R, Philander SGH (1981) Parameterization of vertical mixing in numerical models of tropical oceans. J Phys Oceanogr 11:1443-1451

Peterson LC, Haug GH, Hughen KA, Rohl U (2000) Rapid changes in the hydrologic cycle of the tropical North Atlantic during the last glacial. Science 290:1947-1951

Pritchard HD, Arthern RJ, Vaughan DG, Edwards L (2009) Extensive dynamic thinning on the margins of the Greenland and Antarctic ice sheets. Nature 461(7266):971-975. doi:10.1038/nature08471

Rahmstorf S (2002) Ocean circulation and climate during the past 120,000 years. Nature 419(6903):207-214. doi:10.1038/nature 01090

Rahmstorf S, Willebrand J (1995) The role of temperature feedback in stabilizing the thermohaline circulation. J Phys Oceanogr 25:787-805

Rahmstorf S, Crucifix M, Ganopolski A, Goosse H, Kamenkovich IV, Knutti R, Lohmann G, Marsh R, Mysak LA, Wang Z, Weaver AJ (2005) Thermohaline circulation hysteresis: a model intercomparison. Geophys Res Lett 32:L23605. doi:10.1029/2005 GL023655

Rayner NA, Parker DE, Horton EB, Folland CK, Alexander LV, Rowell DP, Kent EC, Kaplan A (2003) Global analyses of sea surface temperature, sea ice, and night marine air temperature since the late nineteenth century. J Geophys Res 108(D14):4407. doi:10.1029/2002JD002670

Ridley JK, Huybrechts P, Gregory JM, Lowe JA (2005) Elimination of the Greenland ice sheet in a high $\mathrm{CO}_{2}$ climate. J Clim 18:3409-3427

Rignot E, Velicogna I, van den Broeke MR, Monaghan A, Lenaerts J (2011) Acceleration of the contribution of the Greenland and Antarctic ice sheets to sea level rise. Geophys Res Lett 38:L05503

Roche DM (2009) A systematic study of the impact of fresh water pulses with respect to different geographical locations. Clim Dyn. doi:10.1007/s00382-009-0578-8

Rooth C (1982) Hydrology and ocean circulation. Progr Ocean 11:131-149

Roullet G, Madec G (2000) Salt conservation, free surface and varying levels: a new formulation for ocean general circulation models. J Geophys Res 23:927-942

Rypina II, Pratt LJ, Lozier MS (2011) Near-surface transport pathways in the North Atlantic Ocean: looking for throughput from the subtropical to the subpolar gyre. J Phys Oceanogr 41(5):911-925. doi:10.1175/2010JPO4498.1

Saenko OA, Weaver AJ, Robitaille DY, Flato GM (2007) Warming of the subpolar Atlantic triggered by fresh water discharge at the continental boundary. Geophys Res Lett 34:L15604. doi: 10.1029/2007GL030674

Sasgen I, van den Broeke M, Bamber JL, Rignot E, Sørensen LS, Wouters B, Martinec Z, Velicogna I, Simonsen SB (2012) Timing and origin of recent regional ice-mass loss in Greenland.
Earth Planet Sci Lett 333-334:293-303. doi: 10.1016/j.epsl.2012.03.033

Schiller A, Mikolajewicz U, Voss R (1997) The stability of the North Atlantic thermohaline circulation in a coupled ocean-atmosphere general circulation model. Clim Dyn 13(5):325-347

Shimokawa S, Matsuura T (1999) The asymmetry of recirculation of a double gyre in a two layer ocean. J Oceanogr 55:449-462

Stammer D (2008) Response of the global ocean to Greenland and Antarctic ice melting. J Geophys Res 113:C06022. doi: 10.1029/2006JC004079

Steele M, Morley R, Ermold W (2001) PHC: a global ocean hydrography with a high-quality Arctic Ocean. J Clim 14:2079-2087

Sterl A, Bintanja R, Brodeau L, Gleeson E, Koenigk T, Schmith T, Semmler T, Severijns C, Wyser K, Yang S (2011) A look at the ocean in the EC-Earth climate model. Clim Dyn (accepted for publication). doi:10.1007/s00382-011-1239-2

Stommel H (1961) Thermohaline convection with two stable regimes of flow. Tellus 13:224-230

Stouffer RJ, Yin J, Gregory JM, Dixon KW, Spelman MJ, Hurlin W, Weaver AJ, Eby M, Flato GM, Hasumi H, Hu A, Jungclaus JH, Kamenkovich IV, Levermann A, Montoya M, Murakami S, Nawrath S, Oka A, Peltier WR, Robitaille DY, Sokolov A, Vettoretti G, Weber SL (2006) Investigating the causes of the response of the thermohaline circulation to past and future climate changes. J Clim 19:1365-1387

Straneo F, Hamilton GS, Sutherland DA, Stearns LA, Davidson F, Hammill MO, Stenson GB, Rosing-Asvid A (2010) Rapid circulation of warm subtropical waters in a major glacial fjord in East Greenland. Nat Geosci 3(3):182-186. doi:10.1038/ngeo764

Swingedouw D, Braconnot P, Delecluse P, Guilyardi E, Marti O (2007) Quantifying the AMOC feedbacks during a $2 \times \mathrm{CO}_{2}$ stabilization experiment with land-ice melting. Clim Dyn 29:521-534

Swingedouw D, Mignot J, Braconnot P, Mosquet E, Kageyama M, Alkama R (2009) Impact of fresh water release in the North Atlantic under different climate conditions in an OAGCM. J Clim 22:6377-6403

Talley LD, Reid JL, Robbins PE (2003) Data-based meridional overturning streamfunctions for the global ocean. J Clim $16: 3213-3226$

Vizcaíno M, Mikolajewicz U, Jungclaus J, Schurgers G (2010) Climate modification by future ice sheet changes and consequences for ice sheet mass balance. Clim Dyn 34(2-3):301-324. doi:10.1007/s00382-009-0591-y

Walsh KM, Howat IM, Ahn Y, Enderlin EM (2012) Changes in the marine-terminating glaciers of central east Greenland, 2000-2010. Cryosphere 6(1):211-220. doi:10.5194/tc-6-2112012

Winguth A, Mikolajewicz U, Gröger M, Maier-Reimer E, Schurgers G, Vizcaíno M (2005) Centennial-scale interactions between the carbon cycle and anthropogenic climate change using a dynamic earth system model. Geophys Res Lett 32(23):2005

Yin J, Stouffer RJ, Spelman MJ, Griffies SM (2010) Evaluating the uncertainty induced by the virtual salt flux assumption in climate simulations and future projections. J Clim 23:80-96. doi: 10.1175/2009JCLI3084.1

Zhang R (2008) Coherent surface-subsurface fingerprint of the Atlantic meridional overturning circulation. Geophys Res Lett 35:L20705. doi:10.1029/2008GL035463 